\title{
Regionalización biogeográfica de la mastofauna de los bosques tropicales perennifolios de Mesoamérica
}

\author{
Héctor C. Olguín-Monroy ${ }^{1,2}$, Cirene Gutiérrez-Blando ${ }^{1}$, César A. Ríos-Muñoz ${ }^{1}$, \\ Livia León-Paniagua ${ }^{1}$ \& Adolfo G. Navarro-Sigüenza ${ }^{1}$ \\ 1. Museo de Zoología "Alfonso L. Herrera", Facultad de Ciencias, Universidad Nacional Autónoma de México, A. P. \\ 70-399 C.P. 04510, Distrito Federal, México; ninestrell@gmail.com, rmunoz98@ciencias.unam.mx, \\ 1lp@ciencias.unam.mx, adolfon@ciencias.unam.mx \\ 2. Posgrado en Ciencias Biológicas, Universidad Nacional Autónoma de México; Av. Universidad 3000, C.P. 04510, \\ Distrito Federal, México; crokuta@hotmail.com
}

\author{
Recibido 27-II-2012. Corregido 11-IX-2012. Aceptado 11-X-2012.
}

\begin{abstract}
Biogeographic regionalization of the mammals of tropical evergreen forests in Mesoamerica. Mesoamerica is a biologically complex zone that expands from Southern Mexico to extreme Northern Colombia. The biogeographical patterns and relationships of the mammalian fauna associated to the Mesoamerican Tropical Evergreen Forest (MTEF) are poorly understood, in spite of the wide distribution of this kind of habitat in the region. We compiled a complete georeferenced database of mammalian species distributed in the MTEF of specimens from museum collections and scientific literature. This database was used to create potential distribution maps through the use of environmental niche models (ENMs) by using the Genetic Algorithm for Rule-Set Production (GARP) using 22 climatic and topographic layers. Each map was used as a representation of the geographic distribution of the species and all available maps were summed to obtain general patterns of species richness in the region. Also, the maps were used to construct a presence-absence matrix in a grid of squares of 0.5 degrees of side, that was analyzed in a Parsimony Analysis of Endemicity (PAE), which resulted in a hypothesis of the biogeographic scheme in the region. We compiled a total of 41527 records of 233 species of mammals associated to the MTEF. The maximum concentration of species richness (104-138 species) is located in the areas around the Isthmus of Tehuantepec, Northeastern Chiapas-Western Guatemala, Western Honduras, Central Nicaragua to Northwestern Costa Rica and Western Panama. The proposed regionalization indicates that mammalian faunas associated to these forests are composed of two main groups that are divided by the Isthmus of Tehuantepec in Oaxaca in: a) a Northern group that includes Sierra Madre of Chiapas-Guatemala and Yucatan Peninsula; and b) an austral group, that contains the Pacific slope of Chiapas towards the South including Central America. Some individual phylogenetic studies of mammal species in the region support the relationships between the areas of endemism proposed, which suggest a common biogeographical history. In spite that Mesoamerica is considered one of the most important hotspots for biological conservation, the poor knowledge of the biogeographic patterns, the scarcity of protected areas, and the high rate of habitat transformation due to human activities, make prioritary the development of conservation strategies that include patterns of species richness, endemism, and mammalian associations. Rev. Biol. Trop. 61 (2): 937-969. Epub 2013 June 01.
\end{abstract}

Key words: mammals, Mesoamerica, regionalization, parsimony analysis of endemicity, GARP.

La biota mesoamericana muestra patrones biogeográficos influenciados por acontecimientos geológicos y climáticos, que originaron expansiones y contracciones poblacionales, diversificación y extinción de linajes (Savage 1982, Bermingham \& Martin 1998, Burnham \& Graham 1999). Mesoamérica comprende desde
México meridional hasta el norte de Colombia (Savage 1966, Samek 1988, Allen 1990, McCafferty \& Waltz 1990, Morrone 2004a, Sánchez-Osés \& Pérez-Hernández 2005). En la actualidad, se le considera el segundo hotspot más importante después de los Andes Tropicales, no sólo por su rica diversidad y alto 
endemismo, sino también porque en ella aún se encuentran unos $250000 \mathrm{~km}^{2}$ de vegetación primaria a pesar de las presiones humanas (Myers et al. 2000). Además, tiene un papel relevante en la diversidad de plantas debido a sus condiciones climáticas, los factores históricos que han participado en su evolución y la distribución restringida de algunas especies de plantas que habitan en la región (Luna \& Contreras-Medina 2010). Se sabe que en la región habitan alrededor de 24000 especies de plantas vasculares y unas 5000 son endémicas; en cuanto a la fauna, se estiman unas 3300 especies de vertebrados y cerca de un tercio de éstas son consideradas de distribución restringida (Myers et al. 2000, Brooks et al. 2002, Wilson \& Johnson 2010).

Los bosques tropicales perennifolios y subperennifolios (BTP) son considerados entre los tipos de vegetación con mayor rendimiento y diversidad de plantas del planeta (Rzedowski 1981, Prance 1982, Mittermeier 1988, Challenger 1998). En Mesoamérica, México marca el extremo septentrional de su distribución (Rzedowski 1981, Dirzo \& Miranda 1991). La distribución original comprendía toda la Planicie Costera del Golfo de México, la vertiente Pacífica de la Sierra Madre de Chiapas y se prolongaba hacia Centroamérica, donde los BTP son casi continuos en las tierras bajas del Atlántico, desde el sur de México hasta el centro de Panamá (Rzedowski 1981, 1993, Challenger 1998, Duellman 2001). No obstante, los amplios BTP que cubrieron hace tiempo los trópicos húmedos de Mesoamérica han desaparecido en su mayor parte, quedando reducidos a solo $10 \%$ de su extensión original (Rzedowski 1981, Gómez-Pompa 1985, Barrera \& Rodríguez 1993, Wendt 1993, PalacioPrieto et al. 2000, Castellanos et al. 2001, FAO 2002, Díaz-Gallegos \& Mas 2008). Se estima que las áreas de mayor superficie, tanto de BTP como de otros tipos de vegetación primaria, se encuentran en la selva Lacandona al este de Chiapas en México y el Petén de Guatemala; la selva Zoque, constituida por regiones de Chiapas, Oaxaca y Veracruz en México; y los BTP presentes en los valles que se forman entre varias sierras de Guatemala y Honduras (Ewell \& Poleman 1980, Toledo 1982). Estas áreas sobresalen por ser consideradas como un centro de diversidad de plantas y árboles tropicales, por la elevada concentración de especies endémicas de flora y en algunos casos han sido propuestas como refugios Pleistocénicos (Brown 1982, Gentry 1982, Toledo 1982, Wendt 1993, Toledo et al. 1997).

De las 588 especies de mamíferos reconocidas para Mesoamérica, el $44.5 \%$ se distribuye exclusivamente en la región (Flores-Villela \& Navarro 1993, Reid 1997, Samudio 2002, Wilson et al. 2002, Ceballos et al. 2005, Ramírez-Pulido et al. 2005). Aunque en los BTP mesoamericanos, el mono araña (Ateles geoffroyi), el mono ardilla (Saimiri oerstedii), el tapir (Tapirus bairdii), el jaguar (Panthera onca) y el tigrillo (Leopardus wiedii) están entre los mamíferos más carismáticos y amenazados por la extinción, en este tipo de vegetación predominan los murciélagos (March \& Aranda 1992), los cuales constituyen cerca del $50 \%$ de la diversidad de mamíferos en un área dada, mientras que los roedores aportan entre 30 y 35\% (Eisenberg 1990, Medellín 1991). Esta composición biótica hace de los BTP mesoamericanos, uno de los hábitats más diversos en el Neotrópico; propiciado muy probablemente por el surgimiento del Istmo de Panamá, la orogenia Andina durante el Plioceno, así como por las fluctuaciones climáticas asociadas a las glaciaciones durante el Pleistoceno (Toledo 1982, Engel et al. 1998, Collins \& Dubach 2000a, b, 2001, Cortés-Ortíz et al. 2003).

Con el objeto de determinar las relaciones históricas entre las áreas o biotas sobre las cuales especies de diversos taxones se distribuyen (Rosen 1978, Humphries \& Parenti 1986), se han generado al menos cuatro líneas de pensamiento en la biogeografía histórica, y se han propuesto diferentes criterios y métodos de análisis (Brooks \& van Veller 2003), entre ellos el método de Análisis de Parsimonia de Endemismos (PAE, por sus siglas en inglés, Rosen 1988). Este método biogeográfico ha sido aplicado para establecer relaciones entre diferentes 
unidades biogeográficas (Luna et al. 1999, Morrone \& Escalante 2002, Rojas-Soto et al. 2003, Vázquez-Miranda et al. 2007, SánchezGonzález et al. 2008); el PAE aplica un algoritmo de parsimonia con el propósito de obtener un cladograma de áreas, basado en los taxones que habitan las áreas (Rosen 1988, Cracraft 1991, Morrone 1994). Aunque el método ignora las relaciones taxonómicas entre las especies al solo considerar las áreas de distribución, es posible obtener un esquema jerárquico que puede ser utilizado para proponer una regionalización biogeográfica, e incluso puede reflejar eventos vicariantes de relación entre áreas geográficas, a través de la distribución compartida de los taxones (Escalante 2011), y corroborar los resultados con filogenias disponibles de las especies que se encuentran en las áreas (Rosen 1988, Morrone \& Crisci 1995, Morrone 2005a). Aunque el PAE ha sido ampliamente criticado en la literatura, principalmente porque no se le considera un método biogeográfico histórico (Cracraft 1991, García-Barros et al. 2002, Brooks \& van Veller 2003, Peterson 2008), o por la supuesta obtención de relaciones más ecológicas que históricas entre las áreas (TrejoTorres \& Ackerman 2001, Porzecanski \& Cracraft 2005), así como por la utilización de áreas artificiales o incompletas (Nihei 2006, Peterson 2008), su utilidad en biogeografía dependerá en gran medida, tanto de sus objetivos como de datos cada vez más completos que abarquen regiones biogeográficas mucho más grandes (Escalante 2011).

En general, los análisis que conducen a proponer regionalizaciones biogeográficas se basan en datos primarios de biodiversidad; sin embargo, el muestreo en las regiones tropicales mesoamericanas se considera incompleto, por lo que el modelado de nichos ecológicos (MNE) puede constituir una herramienta muy valiosa para solucionarlo (Stockwell \& Peters 1999, Anderson et al. 2002). Los MNE representan las relaciones de las especies con su ambiente, con base en hipótesis de su nicho ecológico y por lo tanto su distribución geográfica (Stockwell \& Noble 1992, Guisan \& Zimmermann 2000, Peterson 2001, Anderson et al. 2003, Soberón \& Peterson, 2005). En este sentido, el Algoritmo Genético de Producción de Conjuntos de Reglas (GARP, por sus siglas en inglés, Stockwell \& Peters 1999), basándose en el concepto de nicho ecológico de Hutchinson (1957), implica un algoritmo computacional evolutivo, que predice las distribuciones geográficas de las especies (Anderson et al. 2002, Peterson et al. 2002a, Martínez-Meyer et al. 2004). Los algoritmos genéticos utilizan un proceso "evolutivo" al azar para solucionar problemas complejos, que generan reglas en función de la distribución de las especies en el espacio ecológico, modificado iterativamente y evaluando las probables soluciones hasta alcanzar una solución "óptima" (Stockwell \& Noble 1992, Stockwell 1999).

En el presente estudio, se propone una hipótesis de biogeografía histórica sobre las relaciones de los BTP mesoamericanos con base en su mastofauna, empleando para ello, MNE generados con GARP, y aplicando el PAE. Este análisis resulta relevante para comprender la historia de la mastofauna mesoamericana, sobre todo porque las selvas altas y medianas de México y Centroamérica no han sido consideradas en conjunto para estudios biogeográficos previos. Esta hipótesis además de documentar los patrones de la mastofauna, permitirá detectar las áreas de endemismo y posteriormente contrastarlas con la filogenia de algunos grupos con la finalidad de conocer la congruencia en las relaciones que guardan (Rosen 1988, Luna et al. 1999, Morrone \& Escalante 2002). Por último, se espera que esta propuesta se tome en cuenta para establecer las estrategias encaminadas a la conservación de uno de los tipos de vegetación más amenazados del planeta (Myers et al. 2000).

\section{MATERIALES Y MÉTODOS}

\section{Área de estudio, definiciones y base de} datos: Para los fines de este trabajo, se consideró a Mesoamérica con base en una construcción biogeográfica, cuyo límite norteño además de demarcar Norte América de Mesoamérica, también divide la región Neártica 
de la Neotropical (Fig. 1). Este concepto de Mesoamérica coincide en gran medida con lo propuesto por algunos autores como Savage (1966), Allen (1990), McCafferty \& Waltz (1990), McCafferty et al. (1992), Morrone (2004a, b) y Wilson \& Johnson (2010).

Para a la delimitación vegetacional de las áreas ocupadas por el BTP en Mesoamérica, se consideraron para México los trabajos de Rzedowski $(1981,1990)$ y en el caso de Centroamérica lo realizado por Wagner (1964), Holdridge (1957) y Holdridge et al. (1971), y se adecuaron a la propuesta de Olson et al. (2001).

Un primer acercamiento a la lista de especies de mamíferos presentes en los BTP mesoamericanos se generó a partir de Reid (1997), Ceballos \& Oliva (2005) y Wilson \& Reeder (2005). En dicha literatura se encuentra información sobre el hábitat para cada especie. Sin embargo, se optó por un criterio amplio para delimitar la lista, debido a que los autores emplean diferentes clasificaciones de vegetación, por lo que se incluyó a las especies presentes que en las fuentes de información se asignaban a los "tropical rain forest" y "tropical evergreen forest" (Leopold 1950), al igual que las de "selva alta perennifolia" y "selva alta o mediana subperennifolia" (Miranda \& Hernández X. 1963), las del "tropical rain forest", el "lower montane rain forest", así como el "evergreen y semi-evergreen seasonal forest" (Breedlove 1973), y por supuesto el "bosque tropical perennifolio" (Rzedowski 1981).

En cuanto al arreglo taxonómico y nomenclatural de la mastofauna, el cual fue realizado hasta en nivel de especie, se sigue lo propuesto por Wilson \& Reeder (2005), y debido a que las diversas fuentes de datos se basan en distintas autoridades taxonómicas, fue necesario realizar una lista de sinonimias o equivalencias taxonómicas (Hall 1981, Wilson \& Reeder

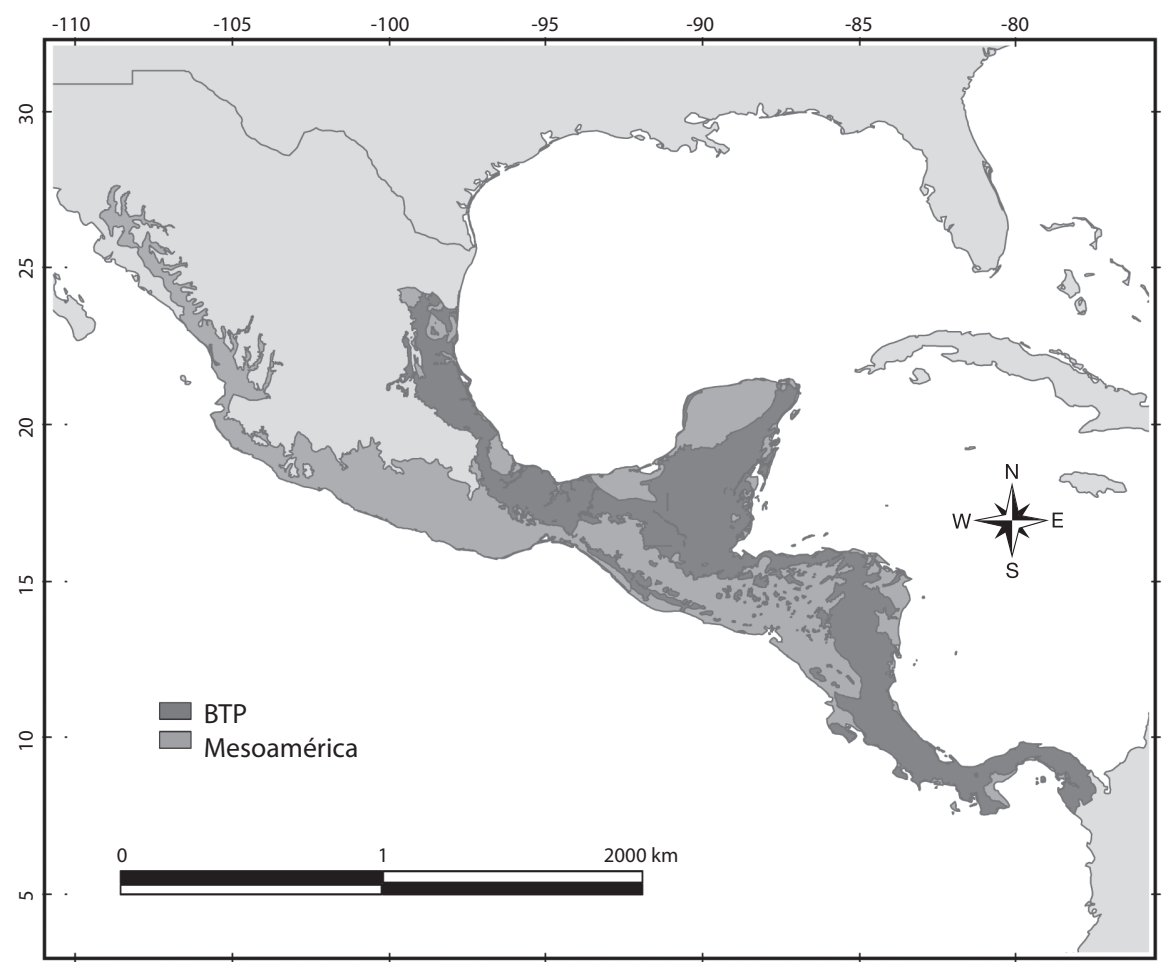

Fig. 1. Distribución de los bosques tropicales perennifolios en Mesoamérica.

Fig. 1. Distribution of tropical evergreen forests in Mesoamerica. 
1993, Ramírez-Pulido et al. 1996, Reid 1997, Ceballos et al. 2002, 2005, Ramírez-Pulido et al. 2005, Wilson \& Reeder 2005), con el propósito de evitar tanto la omisión de datos como la duplicidad de los mismos.

Los registros de presencia primaria para México se extrajeron de la información obtenida a través del Sistema Nacional de Información sobre Biodiversidad (SNIB), perteneciente a la Comisión Nacional para el Conocimiento y Uso de la Biodiversidad (CONABIO), un dato primario es el registro de una especie particular en un punto dado en tiempo y espacio (Peterson et al. 2002b). En el caso de Centroamérica, se recurrió a información en línea de varias colecciones científicas (ver Agradecimientos), además de portales que involucran varias colecciones científicas (Mammal Networked Information System, http://manisnet.org/; Global Biodiversity Information Facility, http:// www.gbif.org/; Arctos, http://arctos.database. museum/home.cfm) y finalmente, a partir de literatura (Allen 1904, 1908, 1910, Goodwin 1942, 1946, 1955, 1969, Hall 1981, Medellín et al. 1998, Paz-Quevedo et al. 2003, Villa-R. \& Cervantes 2003, Tejedor 2005, McCarthy \& Pérez 2006).

Se llevó a cabo un proceso de depuración, detectando los errores nomenclaturales más comunes debido a la captura de datos, sinonimias y ejemplares sin determinar. En cuanto a la sección geográfica, se verificó el nombre de las localidades, su referencia geográfica y cuando fue necesario se asignaron coordenadas geográficas en formato decimal con una exactitud de $0.01^{\circ}$, empleando atlas nacionales e internacionales (INEGI 1982), gaceteros regionales (Goodwin 1969, Selander \& Vaurie 1962) o informáticos (e.g. Alexandria Digital Library, http://www.alexandria.ucsb.edu/; BioGeomancer Project, http://www.biogeomancer. org/; Fallingrain Global Gazetteer, http://www. fallingrain.com/world/index.html). Además se revisó que los registros coincidieran con los límites de la distribución conocida para cada especie, eliminando los datos de áreas donde no se ha registrado su presencia de manera fidedigna (Hall 1981, Reid 1997, Ceballos \& Oliva 2005, Wilson \& Reeder 2005).

El modelado de nichos ecológicos: Para eliminar los sesgos y ausencias de recolecta que se tienen en las bases de datos biológicas conformadas solamente por datos puntuales, se realizaron MNE para poder generar una hipótesis de la distribución potencial de las especies, tal como se ha hecho en otros estudios biogeográficos (Rojas-Soto et al. 2003, Sánchez-González et al. 2008).

De manera general, el témino "nicho" hace referencia a las condiciones ecológicas que una especie requiere para mantener poblaciones en una región determinada (Peterson et al. 2011). Entonces, los métodos para modelar la distribución de las especies combinan puntos de ocurrencia conocida con capas ambientales continuas espacialmente para inferir los requerimientos ecológicos de la especie. De esta manera, la distribución geográfica de una especie es predicha mapeando el área donde estos requerimientos ambientales se cumplen (Hernández et al. 2006), quedando definidos dos espacios: el espacio geográfico, representando la geografía y el espacio ecológico representado por las condiciones ambientales presentes en el espacio geográfico. Por lo tanto, los nichos y las distribuciones son estimados y visualizados en espacios geográficos y ambientales asociados (Peterson et al. 2011).

El presente trabajo, utilizó el algoritmo GARP (Stockwell \& Noble, 1992) para generar las distribuciones potenciales de 192 especies, mediante su implementación para PC DesktopGARP (Scachetti-Pereira 2003). GARP es un algoritmo que establece relaciones no aleatorias entre los registros biológicos y las coberturas ambientales que son utilizadas en la elaboración del modelo (Stockwell \& Peters 1999). Este último es una representación de las condiciones requeridas por la especie basándose en el concepto de nicho ecológico (Hutchinson 1957, Stockwell \& Peters 1999). Aunque GARP ha recibido varias críticas, éstas se han centrado en la evaluación de los modelos generados mediante el cálculo del área bajo la curva 
ROC (Receiver Operating Characteristics, Elith et al. 2006) ó el alto error de comisión en los modelos (Phillips et al. 2006). Sin embargo, ambas críticas carecen de argumentos claros. El caso de las evaluaciones de los modelos con las curvas ROC ha sido criticado ya que tienden a favorecer el sobreajuste (Lobo et al. 2007).

Además dichas evaluaciones son realizadas utilizando toda el área incluyendo valores que no son informativos (Peterson et al. 2008). Al realizar un análisis comparativo en distintos modelos por medio de pruebas de ROC parcial a los valores de presencia, que son informativos, GARP presenta mejores resultados que otros modelos (Peterson et al. 2008). En todos los casos la exactitud de los modelos es evaluada a través de puntos de validación escogidos aleatoriamente en el área de estudio (Wiley et al. 2003). El algoritmo GARP presenta errores de omisión bajos, condición que lo hace un buen modelo ya que tiene un éxito predictivo alto (Hernández et al. 2006), no sólo en cuanto a mamíferos (Illoldi-Rangel et al. 2004, Sánchez-Cordero et al. 2005) sino también en aves (Peterson et al. 2000), anfibios y reptiles (García 2006). En ese sentido, MaxEnt tiene una incapacidad relativa para predecir en regiones amplias no muestreadas, al menos con niveles de alta probabilidad (Peterson et al. 2007).

Para generar los MNE se utilizaron un total de 22 coberturas climáticas (oscilación diurna y anual de la temperatura, isotermalidad, estacionalidad de la temperatura y precipitación, temperaturas máxima y mínima promedio de los periodos más cálidos y fríos respectivamente, temperaturas promedio anual, de los trimestres más lluvioso, seco, cálido y frío, precipitación anual, de los periodos más lluvioso, seco y de los trimestres más lluvioso, seco, cálido y frío; http://www.worldclim.org, Hijmans et al. 2005) y topográficas (altitud, pendiente e indice topográfico; http:// edcdaac.usgs.gov/gtopo30/hydro, Proyecto Hydrolk). Para cada especie se generaron 100 modelos escogiendo los 10 mejores siguiendo la propuesta de Anderson et al. (2003), que considera aquellos con la menor omisión y una comisión moderada. Estos mejores modelos se sumaron y los valores de presencia fueron considerados donde coincidieran al menos siete de los diez modelos ( $70 \%$ de coincidencia), ya que se observó que este valor representaba de manera adecuada los datos puntuales. La delimitación de las áreas de distribución de las especies se realizó acotando la predicción generada por el modelo dentro de las ecorregiones en las cuales existían datos históricos de presencia, considerando que estas regiones se pueden utilizar para definir los límites de la distribución de las especies (Rojas-Soto et al. 2003, Soberón \& Peterson 2005, IlloldiRangel \& Escalante 2008).

Finalmente, a partir de la superposición de las hipótesis de distribución generadas, fue posible identificar las regiones de mayor riqueza, y de concentración de especies endémicas a Mesoamérica, estableciendo con ello, escalas de riqueza para la región.

\section{Análisis de parsimonia de endemismos:} Se optó por el empleo del PAE para reconstruir afinidades bióticas mastofaunísticas en los BTP mesoamericanos, con la intención de obtener un esquema jerárquico que se utilizó para proponer una regionalización biogeográfica (Escalante 2010). Este método agrupa áreas (análogo a las especies), con base en las especies compartidas (análogas a los caracteres) (Morrone 1994, Pires et al. 2000, Bisconti et al. 2001), de acuerdo con la explicación más simple para todas las distribuciones (Morrone \& Crisci 1995, Escalante \& Morrone 2003).

Se utilizó una gradilla de un tamaño de celda de 0.5 grados, la cual cubrió el área de estudio y sirvió como base para la construcción de la matriz de presencia-ausencia (374 cuadros), con solo 192 hipótesis de distribución de los mamíferos presentes en los BTP mesoamericanos, debido a que no hubo suficientes datos primarios para 41 especies, $17 \mathrm{de}$ éstas endémicas a Mesoamérica, y dado que la intención de este trabajo fue detectar patrones generales, se incluyó una especie en una celda al momento de construir la matriz, si la hipótesis de distribución intersectaba a la misma, sin 
importar la proporción del área de la celda que esta cubriera. Dicha matriz se codificó con "1" ó "0" como presencia o ausencia de la especie, respectivamente. Se aplicó el enraizamiento de Lundberg, agregando un área "externa" hipotética con "0" en todas las casillas, para orientar el cladograma (Rosen 1988, Morrone 1994). El análisis se realizó en el programa Nona 2.0. (Goloboff 1994) y su interfase Winclada, versión 0.9.99 (Nixon 2000), mediante una búsqueda de parsimonia de matraca (ratchet, Nixon 1999) y con los parámetros predeterminados por el programa, y una vez obtenidos todos los árboles igualmente parsimoniosos, se llevó a cabo un consenso estricto el cual sirvió de base para proponer una hipótesis de relación entre las áreas de BTP mesoamericano.

Finalmente, se les asignaron nombres a los grupos formados en el análisis, con base en regionalizaciones propuestas con anterioridad (Ryan 1963, Savage 1974, Ramírez-Pulido \& Castro-Campillo 1990, Escalante et al. 2002, Morrone 2001a, Morrone et al. 2002). Sin embargo, en el caso de regiones no reconocidas en dichas propuestas, se les designó uno en función del área que abarcan, o se asociaron a los sitios en donde inician y terminan separados por un guión. Los nombres designados en el presente trabajo se marcaron con un asterisco (*) para distinguirlos.

\section{RESULTADOS}

Base de datos y el modelado de nichos ecológicos: La base depurada contiene un total de 41527 registros para las 233 especies de mamíferos reconocidas en los BTP de Mesoamérica (Apéndice 1), distribuidas en 19953 localidades únicas en todo México y Centroamérica (ver Agradecimientos).

Mediante la agregación de hipótesis de distribución geográfica (suma de mapas), fue posible apreciar tanto las regiones con mayor riqueza de especies (192 MNE), como las de concentración elevada de especies de mamíferos de los BTP mesoamericanos restringidos a esta región (49 hipótesis). Las regiones de alta riqueza de especies abarcan una escala comprendida entre 104 y 138 especies, mientras que las áreas con alto endemismo abarcan de 13 a 16 especies. En la figura 2 se aprecian las regiones que concentran una alta riqueza: el sureste de México; la región del Petén en Guatemala; los BTP intermontanos entre Guatemala y Honduras; la Cordillera Centroamericana, extendiéndose desde Honduras hasta la Sierra

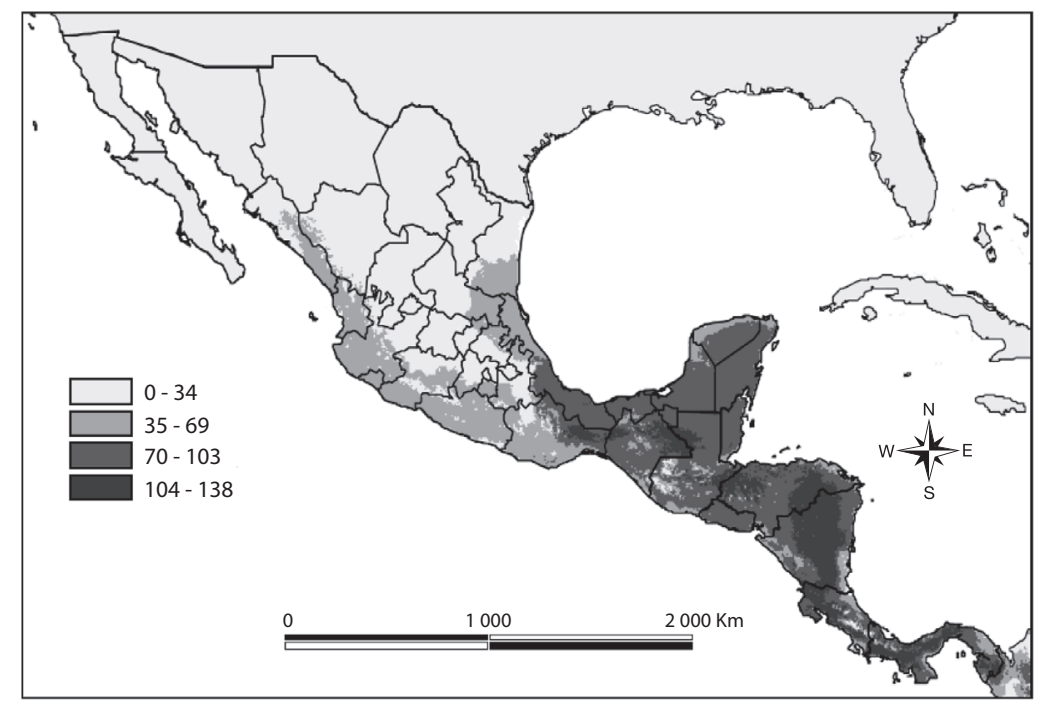

Fig. 2. Regiones mesoamericanas que concentran una alta riqueza de mamíferos de BTP.

Fig. 2. Mesoamerican regions with a high concentration of mammal species richness in tropical evergreen forests. 
Tabasará al centro de Panamá; finalmente la Región del Darién al este de Panamá. En la figura 3 se aprecian las áreas con alto endemismo: algunas regiones del sureste mexicano, el Altiplano Montañoso de Guatemala, gran parte de El Salvador, cruzando el sur de Honduras hasta el noroeste de Nicaragua, y la Cordillera de Tilarán al oeste de Costa Rica.

Análisis de parsimonia de endemismos: El PAE originó cuatro árboles igualmente parsimoniosos, con una longitud de 2037 pasos, un índice de consistencia $(\mathrm{CI})$ de 0.9 y un índice de retención (RI) de 0.87 y se plantea una regionalización con base en el consenso estricto (80 nodos colapsados; Figs. 4, 5 y 6, Cuadro 1).

En el cladograma de consenso generado es posible detectar patrones bien definidos. Lo primero que se aparta es un grupo formado por las partes bajas de la Gran Sierra Plegada en la Sierra Madre Oriental, seguido por la Huasteca*, posteriormente se desprenden varios grupos, apoyados por tres especies de murciélagos (Cuadro 1; Chrotopterus auritus, Hylonycteris underwoodi y Peropteryx kappleri), el primer grupo es uno pequeño que corresponde al este de la Faja Volcánica Transmexicana, a continuación se encuentran tres regiones del
Golfo de México (Chiconquiaco*, Los Tuxtlas y Zonas no inundables de Tabasco*), seguidas por el grupo Juchitán* al norte del Istmo de Tehuantepec y otra en Los Altos de Chiapas. A continuación, la mastofauna reconocida para los BTP mesoamericanos se dividide en dos grandes grupos, el grupo septentrional comprende desde el Istmo de Tehuantepec en Oaxaca y el norte de la Sierra Madre de Chiapas-Guatemala; el segundo es un grupo austral, sustentado por Micronycteris hirsuta (Cuadro 1), que contiene la vertiente pacífica desde el Istmo de Tehuantepec hacia el sur e incluye a toda Centroamérica.

El clado Yucatán y Pantanos de Centla*, el más septentrional de los dos grandes grupos, se conforma a partir de Los Altos de Guatemala, seguido por la Sierra Lacandona, El PeténBelice*, posteriormente y a otro nivel, soportados por Otonyctomys hatti y Mazama pandora (Cuadro 1), se une la región de los Pantanos Tabasqueños de Centla-Champotón*, y por el otro la Península de Yucatán.

El segundo clado es el más austral, se establece desde el Istmo de Tehuantepec y está conformado en un principio por seis grupos al mismo nivel, un grupo muy definido que se extiende desde Oaxaca hasta El Salvador, denominado Tehuantepec-Usulután*; los BTP

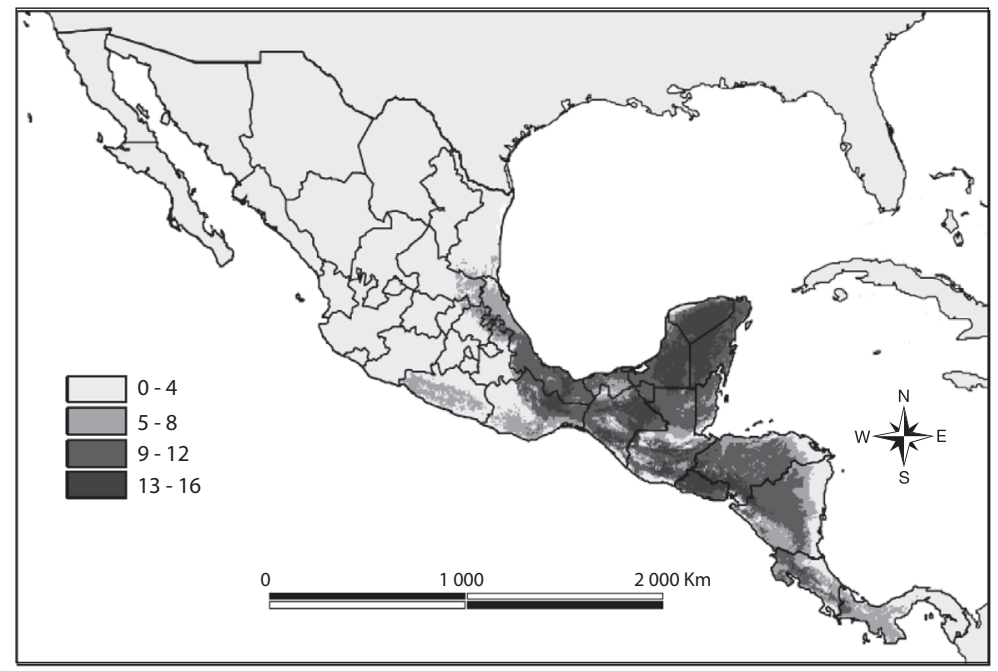

Fig. 3. Áreas con alto endemismo en mamíferos del BTP mesoamericano.

Fig. 3. Areas with a high concentration of endemic species richness in Mesoamerican tropical evergreen forests. 


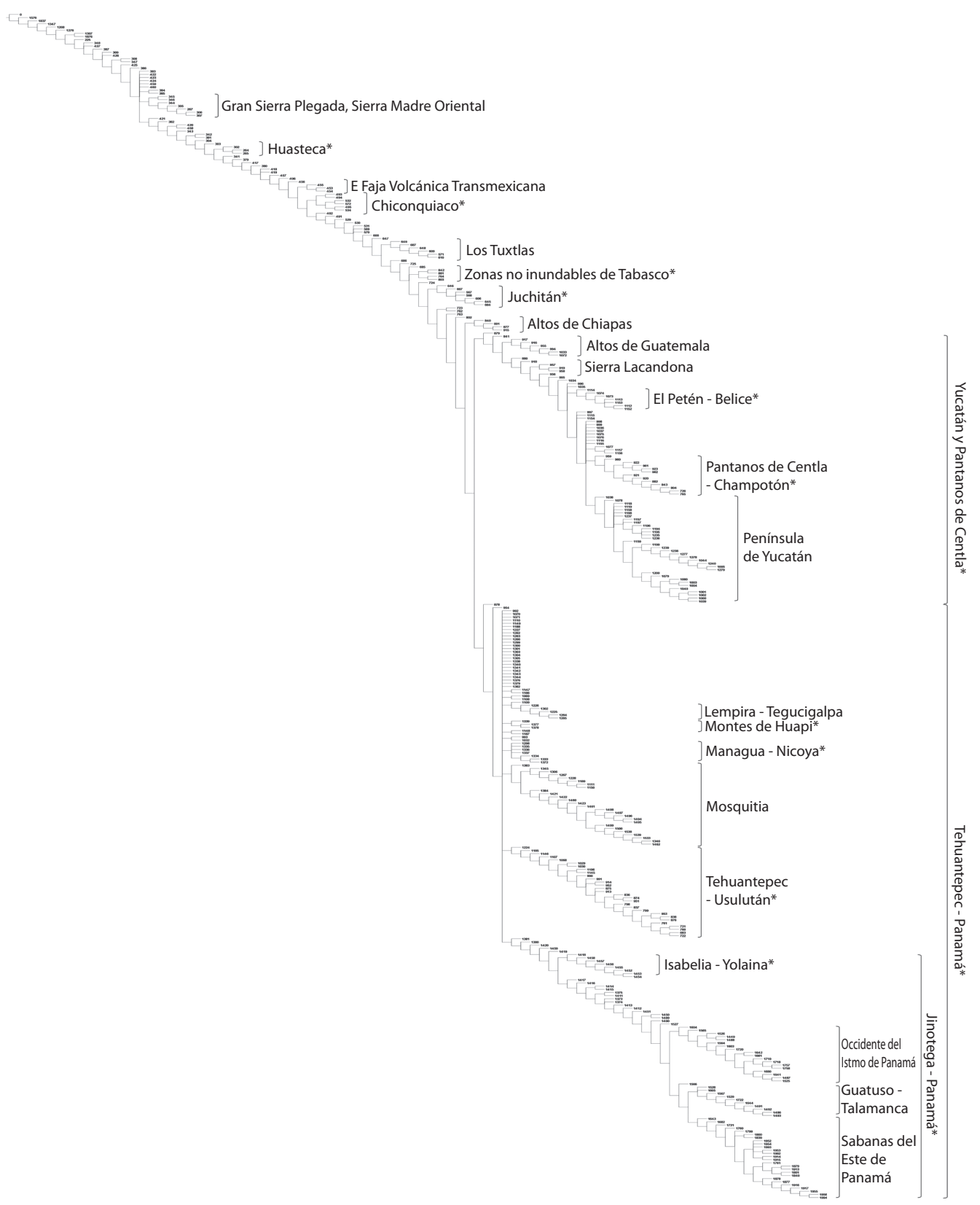

Fig. 4. Cladograma de consenso estricto obtenido con todos los mamíferos reconocidos para los BTP mesoamericanos. Fig. 4. Strict consensus cladogram obtained using all the mammal species registered for the Mesoamerican tropical evergreen forest. 


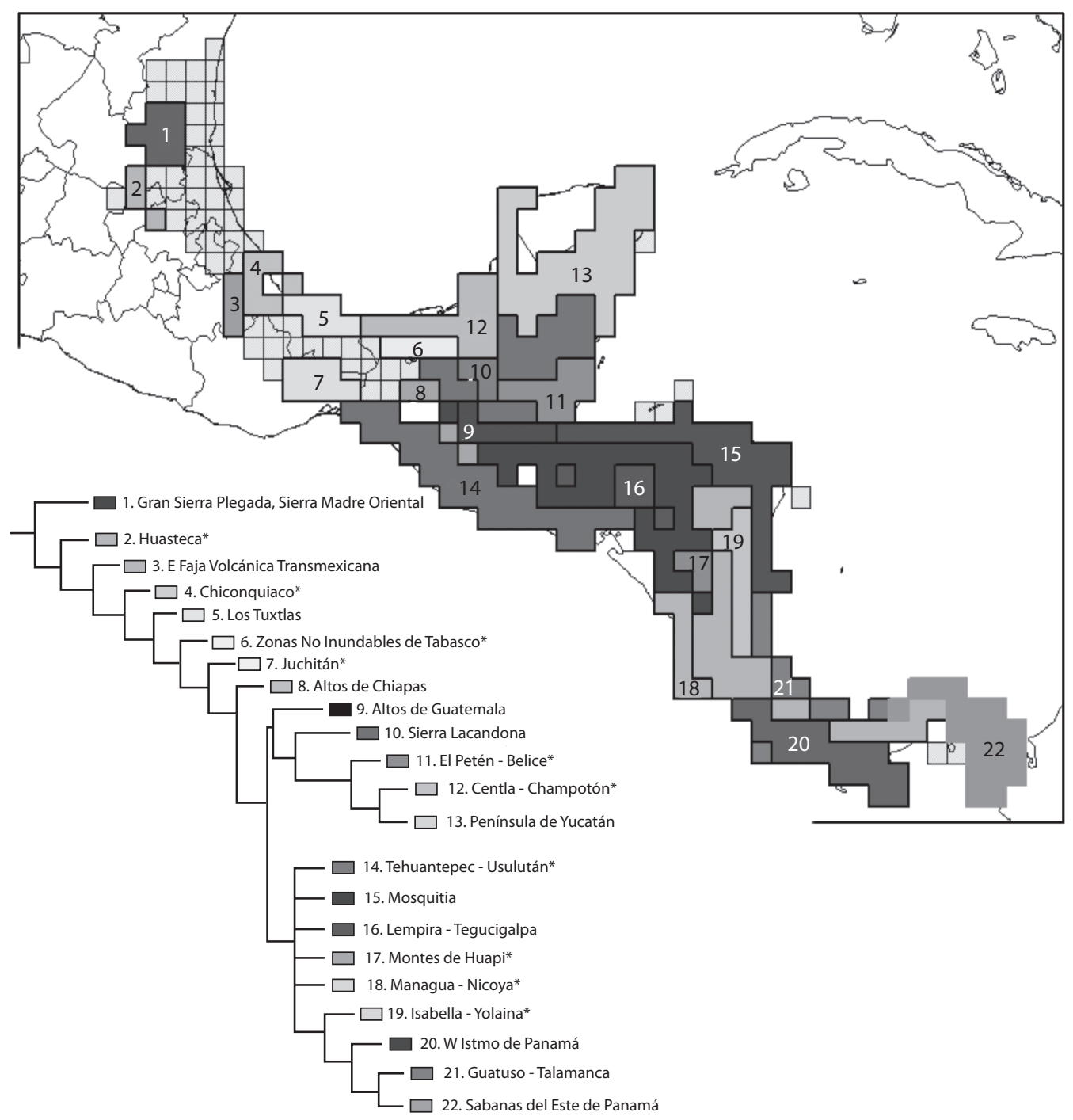

Fig. 5. Regionalización en secuencia, lograda a través del PAE y el empleo de todas las especies de mamíferos. A la izquierda, la formación del cladograma simplificado y a la derecha las áreas de endemismo halladas.

Fig. 5. Sequence regionalization, obtained through the use of PAE with all mammal species recorded. To the left, simplified cladogram; to the right, Areas of endemism found.

del litoral caribeño, a partir del Golfo de Honduras, abarcando toda el área de Mosquitia; el conformado por Lempira-Tegucigalpa, posteriormente aparecen los Montes de Huapi* y Managua-Nicoya*; el último comprende desde Nicaragua, y se designó Jinotega-Panamá*, el cual se subdivide iniciando por una zona de cordilleras Isabelia-Yolaina*; consecutivamente se ensambla un clado, apoyado por dos especies de Oryzomys (Cuadro 1), y que corresponde al Occidente del Istmo de Panamá, el cual se divide en la región de GuatusoTalamanca y las Sabanas del este de Panamá, ésta última región soportada por los roedores 


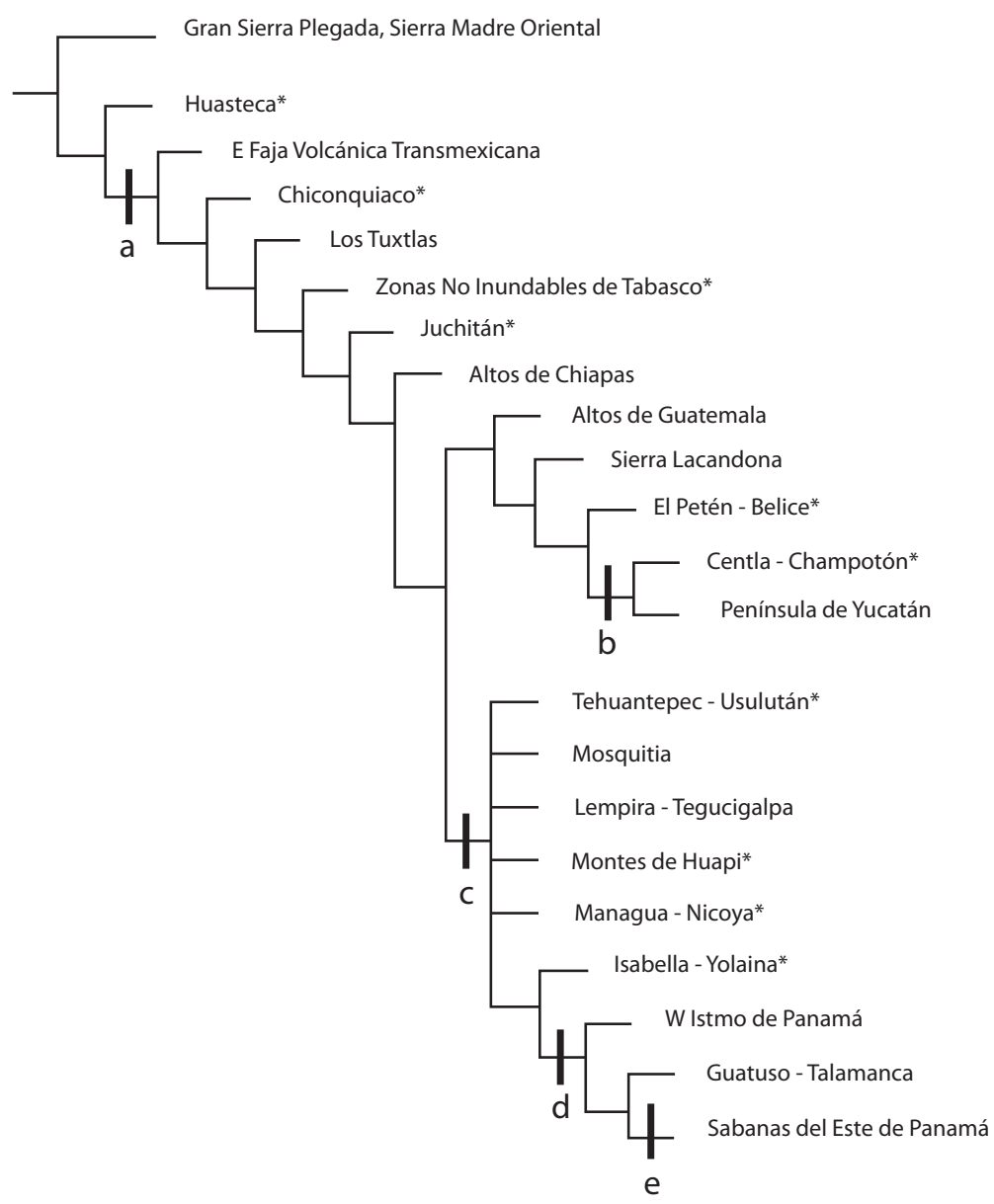

Fig. 6. Cladograma consenso estricto (resumido).

Fig. 6. Strict consensus cladogram (simplified).

\section{CUADRO 1}

Nodos del cladograma consenso estricto (resumido), denotando las sinapomorfias y autapomorfias halladas

TABLE 1

Strict consensus cladogram nodes (simplified), highlighting the synapomorphies and autapomorphies found

\begin{tabular}{cl} 
Nodo & \multicolumn{1}{c}{ Especies } \\
a & Chrotopterus auritus, Hylonycteris underwoodi y Peropteryx kappleri \\
b & Otonyctomys hatti y Mazama pandora \\
c & Micronycteris hirsuta \\
d & Oryzomys devius y O. talamancae \\
e & Heteromys australis e Isthmomys pirrensis \\
\hline
\end{tabular}

Nota: los nodos sostenidos por una especie no son considerados estrictamente como áreas de endemismo, sin embargo existen potencialmente otras especies que los soportan. 
Heteromys australis e Isthmomys pirrensis (Cuadro 1).

\section{DISCUSIÓN}

Bases de datos y el modelado de nichos ecológicos: Se tuvo acceso a bases independientes, sin embargo, mucha de la información no se encuentra actualizada, incluso se ha estimado que las sinonimias abarcan entre un 10 y $30 \%$ de los nombres en muchas bases (Gaston \& Mound 1993, Alroy 2002). Otro tipo de problemas inherentes a las bases de datos, implicaron una mala determinación de un número relativamente importante de ejemplares, además de localidades inexactas o la asignación incorrecta de coordenadas geográficas. Algunos de estos problemas con las bases de datos disponibles en línea ya habían sido señalados por Contreras-Medina \& Luna (2007). No obstante, se consultaron las equivalencias taxonómicas y la información geográfica de la distribución para cada especie (Soberón \& Peterson 2004), y aunque se perdió cerca del $30 \%$ de la información durante la depuración, se estima que la representación de datos primarios fue muy buena, sobre todo si se compara con biomas en los que se presenta una menor diversidad y una mayor proporción de especies restringidas.

Si bien existe bastante información digitalizada de varios museos (Krishtalka \& Humphrey 2000), para algunas regiones de Guatemala, Honduras y Nicaragua, así como para muchas de las especies centroamericanas, no se encontraron registros suficientes; sin embargo, el empleo de un modelo predictivo, hizo posible cubrir grandes huecos en la distribución de las especies (Peterson et al. 1998, 2002, Peterson \& Cohoon 1999). Además el GARP permitió incrementar la cobertura y resolución de 45 especies, a pesar de que se habían obtenido entre cinco y 15 datos de presencia, valores por debajo de lo sugerido por Peterson \& Cohoon (1999), pero similares a lo propuesto por Stockwell \& Peterson (2002a); dichos acercamientos proporcionan una herramienta capaz de construir modelos de distribución con base en datos incompletos (Peterson et al. 1999, Peterson 2001, Stockwell \& Peterson 2002b, Illoldi-Rangel et al. 2004).

Riqueza de especies y endemismo: La región reconocida como Mesoamérica es rica en especies de mamíferos con un alto número de especies que le son exclusivas. A pesar de que Croizat (1976) incluye toda la región en un nodo Mesoamericano-Antillano, al parecer los BTP mesoamericanos no son una unidad homogénea en cuanto a su mastofauna, en éstos predomina el elemento Mesoamericano Tropical, equivalente a los trazos generalizados Sudamericano de Savage $(1966,1982)$ y Meridional de Morrone \& Márquez (2001), mientras que en la Península de Yucatán se encuentra también el elemento Antillano (Rzedowski 1981, Chiappy-Jones et al. 2001, Ibarra-Manríquez et al. 2002, Chakrabarty 2006, Lovette \& Rubenstein 2007), por lo que su condición de unidad natural debería revisarse.

En relación al mapa de concentración de especies, es evidente que todas las regiones consideradas de mayor riqueza potencial de mamíferos, responden principalmente a una topografía compleja, y con ello, a una gran variedad de climas, ambientes y tipos de vegetación, condiciones que mantienen una mezcla impresionante de especies de climas templados y tropicales. Además coinciden con lo hallado para la flora del área en las regiones de El Arco que implica parte de la Selva Zoque; Izabal que comprende el sur del Petén, Izabal y Alta Verapaz en Guatemala, y el sur de Belice; y el norte de Centro América (Toledo 1982, Wendt 1989), insectos (McCafferty et al. 1992, Morón 1992, Schuster 1992), anfibios (Campbell 1999), y aves (Hawkins et al. 2006, Patten \& Smith-Patten 2008). En el caso del mapa de riqueza potencial de la mastofauna endémica, es posible apreciar que las regiones con mayor concentración de especies exclusivamente mesoamericanas también coinciden con algunos refugios pleistocénicos más pequeños y discretos en el sureste de México y el norte de Centro América (Toledo 1982). Algunos autores señalan que varias especies de plantas 
se encuentran restringidas a la región del sur de Veracruz, así como la parte occidental de la Selva Lacandona y el área de Izabal (Toledo 1982, Wendt 1989, 1993, Gentry 1992). Esta región coincide significativamente con el refugio boscoso paleoecológico guatemalteco reconocido con mariposas (Brown 1982, 1987a), y un área de endemismo para aves (Haffer 1987). Además también se incluyen algunos centros de endemismo más discretos, como las tres áreas de precipitación alta en México (Los Tuxtlas, Tuxtepec y Uxpanapa) y partes del oriente de Guatemala y sur de Belice (Lundell 1942, Miranda 1958, Toledo 1982).

Otra región que también destaca por un número considerable de endemismos es la Península de Yucatán, no solo para la mastofauna (e.g. Cryptotis mayensis, Rhogeessa aeneus, Alouatta pigra, Sciurus yucatanensis, Heteromys gaumeri, Otonyctomys hatti, Peromyscus yucatanicus y Mazama pandora; Escalante et al. 2002, 2003b, 2007), sino que también esta área corresponde a una zona de endemismo de especies de flora (Standley 1930, Lundell 1937, Miranda 1958, Rzedowski 1981, Durán \& Olmsted 1987, Estrada-Loera 1991, Gentry 1992, Wendt 1993), de peces de agua dulce (Miller 1966) y para anfibios y reptiles (Duellman 1966, Savage 1966, 1982, 2002, Campbell 1999).

Se han propuesto varios modelos que pretenden explicar el origen de esta elevada diversidad en los organismos neotropicales, incluyendo a los mamíferos. Recientemente, la atención se ha centrado en varios mecanismos que fueron muy activos durante el Pleistoceno, como la formación de refugios pleistocénicos, divergencia parapátrica debido a gradientes ecológicos agudos, cambios climáticos, entre otros (Simpson \& Haffer 1978, Haffer 1982, Endler 1982, Morain 1984, Prance 1987, Brown 1987b, Bush 1994, Colinvaux 1996, Kinzey 1997). Sin embargo, aún no se alcanza ningún acuerdo en relación con la validez general de alguno de los modelos de diversificación propuestos, y tampoco son mutuamente excluyentes. Sin embargo, se ha logrado establecer que la orogenia andina, el surgimiento del Istmo de Panamá, los ríos y refugios de los BTP, en ese orden, jugaron importantes papeles en la diversificación de los mamíferos (Patton \& Smith 1992, Collins \& Dubach 2000a, Cortés-Ortiz et al. 2003, Hoffman \& Baker 2003). Mientras que para el resto de la biota, los eventos vicariantes en la región, así como los sistemas montañosos mesoamericanos han influido de manera importante en los patrones de riqueza y endemismo para la flora y la fauna de Mesoamérica (Binford 1989, Ceballos \& Navarro 1991, Luna-Vega \& Llorente 1993, Campbell 1999, Peterson et al. 1999, Watson \& Peterson 1999, Ortega-Gutiérrez et al. 2000, Carleton et al. 2002, Savage 2002, Escalante et al. 2003a, Mulcahy et al. 2006, Rogers et al. 2007, Wilson \& Johnson 2010). De este modo, la peculiar historia geológica y evolutiva mesoamericana se ha traducido no solo en un alto grado de diversidad sino también de endemismos. Inclusive, Mesoamérica ha sido propuesta como una entidad biogeográfica distinta, en función de la composición histórica y actual de su biota (Savage 1966, Lot \& Novelo 1992, McCafferty et al. 1992, Köhler 2003).

Patrones biogeográficos de la mastofauna derivados del PAE: En el presente trabajo, los grupos Yucatán y Pantanos de Centla*, y Tehuantepec-Panamá* se resuelven satisfactoriamente, sugiriendo que las mastofaunas restringidas a estas regiones son claramente distinguibles. Sin embargo, también se presentan algunas politomías en la base del cladograma de consenso. Rosen (1988) sugiere que los gradientes ecológicos o las zonas de transición probablemente sean los responsables. No obstante, coincidimos con Sánchez-González et al. (2008), quienes mencionan que al emplear MNE lo más probable es que este arreglo se deba a que algunas celdas presentan una baja riqueza en el número de especies, ya sea por hallarse en el borde, conteniendo una superficie reducida del área de estudio o a que las celdas contienen pequeños remanentes de la vegetación analizada.

El planteamiento generado, mostró una correspondencia geográfica bien estructurada y 
consistencia elevada. La propuesta se divide en dos grupos bien definidos, el grupo septentrional denominado Yucatán y Pantanos de Centla*, que inicia desde el Istmo de Tehuantepec y el norte de la Sierra Madre de Chiapas-Guatemala; y el grupo austral, designado Tehuantepec-Panamá*, constituido por toda la vertiente pacífica, desde el Istmo de Tehuantepec y hacia el sur, abarcando la totalidad de Centroamérica. La hipótesis referida resulta interesante, pues se asemeja en mucho a la regionalización fitogeográfica del Caribe propuesta por Samek (1988), donde reconoce para Mesoamérica dos provincias biogeográficas: Golfo de México y Guatemala-Panamá; la primera constituida por una franja que implica las tierras bajas desde Tamaulipas hasta el noroeste de Honduras, además de la Península de Yucatán, y la segunda que se extiende por la costa del Caribe, desde Guatemala hasta Panamá; planteamientos también similares a los señalados por Good (1974), Gentry (1982) y Morrone (2001a, b, 2004a, b). Asimismo, muchos de los límites biogeográficos propuestos en el presente trabajo coinciden con los establecidos por Patten \& Smith-Patten (2008) para aves mesoamericanas, obtenidos mediante el algoritmo de Monmonier's.

El clado Yucatán y Pantanos de Centla* es el grupo septentrional y se asemeja en gran medida a la provincia Campechana, perteneciente a la subregión Tierras Bajas del Este planteada por Savage (1966), excepto por sus límites meridionales; característica que si comparte con la Península de Yucatán señalada por Goldman \& Moore (1946) y Yucatán de Ryan (1963). Barrera (1962) menciona que los límites de esta provincia varían con los distintos taxones analizados, debido al efecto de peninsularidad que determina gradientes para la flora y la fauna.

Morrone (2004a, b), aparta a la provincia Península de Yucatán del dominio Mesoamericano, situándola en el Antillano; su flora presenta numerosos elementos antillanos, aunque de acuerdo con Rzedowski (1981), esta influencia sería menor que la de la provincia del Golfo de México. Durán et al. (1998), determinan la presencia de elementos florísticos antillanos, centroamericanos y del sureste mexicano. Asimismo, se ha sugerido un estrecho vínculo florístico (Little \& Barrington 2003, Trénel et al. 2007, Ramírez-Morillo et al. 2010) y faunístico de esta provincia con las Antillas (del Hoyo et al. 1992, Lovette \& Bermingham 1999, Chakrabarty 2006, Overton \& Rhoads 2006, Lovette \& Rubenstein 2007, Wahlberg \& Freitas 2007, Bellemain et al. 2008). En cuanto a elementos endémicos de su flora, se ha sugerido que su presencia responde muy probablemente a condiciones que prevalecieron durante el Pleistoceno, tanto edáficas, con suelos calcáreos y poco desarrollados, como paleoclimáticas, con ambientes secos (Kruckeberg \& Rabinowitz 1985, Rzedowski 1991). Aunque, al relacionar muchos patrones faunísticos con una reconstrucción tectónica de América (Müller et al. 1999, Rogers 2003), es posible detectar que las rupturas tectónicas ocurridas en los márgenes de la placa del Caribe en el Cenozoico temprano, pueden ser las responsables de producir muchas de las divisiones filogenéticas (Collins \& Dubach, 2000a, b, 2001, Cortés-Ortiz et al. 2003, Collins 2004). Finalmente, es posible reconocer unidades menores, en el interior del clado, que podrían contribuir al reconocimiento de distritos, similares a los obtenidos con taxones vegetales (Espadas-Manrique et al. 2003).

El grupo Tehuantepec-Panamá* es el clado austral, abarca Centroamérica en su totalidad, y sus límites son semejantes a los establecidos por Samek (1988) para la provincia Guatemala-Panamá, por Cracraft (1985) para Centroamérica, y por Morrone (2004a, b) para el dominio Mesoamericano. Asimismo, este grupo coincide en gran medida con patrones hallados en aves (del Hoyo et al. 1992), peces dulceacuícolas (Concheiro-Pérez et al. 2007), entre otros; y se ha encontrado evidencia de una relación muy cercana con América del Sur (Saslis-Lagoudakis et al. 2008, Weir et al. 2009), donde la división principal coincide con una sutura mesozoica denominada Falla de Romeral, ubicada en la Cordillera Andina, al oeste de Colombia (Rogers 2003).

En cuanto a los subgrupos, se encuentra Tehuantepec-Usulatán* contenido en 
provincias identificadas por Samek (1988), Savage (1982) y Morrone \& Márquez (2001); Mosquitia abarca parte del litoral caribeño y se asemeja a otras propuestas (Ryan 1963, Savage 1966); Lempira-Tegucigalpa equivalente a la reconocida por Ryan (1963) y Savage (1966); Montes de Huapi* y Managua-Nicoya*. Continuando con la politomía y al mismo nivel de los anteriores subgrupos, se halla JinotegaPanamá*, área que presenta algunos patrones anidados, que corresponden a provincias establecidas anteriormente (Savage 1966, Morrone \& Márquez 2001). Por último, un clado equivalente a la provincia Chocó o Sabanas del Este de Panamá (Savage 1966, 1982); y al igual que en el septentrional, en este clado también se reconocen algunas unidades menores que podrían tratarse a nivel de distritos.

El clado Tehuantepec-Panamá*, así como algunos de los patrones anidados en el subgrupo Jinotega-Panamá*, no se sustentan por especies endémicas, en general el grupo se soporta por especies de afinidad neotropical. La carencia de especies endémicas en la definición de los grupos, en gran medida se explica por la edad relativamente reciente del actual BTP (Rzedowski 1981); aunque cabe la posibilidad de que los cambios de clima en el Pleistoceno y sus consecuencias en la vegetación mesoamericana no han sido suficientes para incidir en los procesos de especiación.

Se sabe que los eventos geológicos son previos a la etapa de diversificación de los mamíferos por lo que los resultados de la regionalización podrían estar dando una idea de las condiciones ecológicas presentes en los BTP en función de su mastofauna. Sin embargo, los procesos de diversificación ocurrieron paralelamente en distintos grupos, por lo que es necesario contrastar las áreas de endemismo halladas con la filogenia de algunos grupos con la finalidad de conocer las relaciones que guardan dichas áreas.

Algunos táxones presentan distribuciones congruentes con la regionalización obtenida a lo largo del BTP mesoamericano (e.g. Alouatta monos aulladores, Ateles mono araña, Sciurus ardillas, Heteromys ratones espinosos,
Rhogeessa murciélagos y Mazama temazates, Reid 1997, Ceballos \& Oliva 2005), cada uno tiene por lo menos una especie o más en cada uno de los grupos. Trabajos realizados sobre las relaciones de ancestría común, así como morfométricos y cariotípicos para algunos de estos taxones muestran una conformación geográfica marcada de ambos clados (Engstrom et al. 1987, Schmidt et al. 1989, Audet et al. 1993, Genoways \& Baker 1996, Silva-Lópes et al. 1996, Madeiros et al. 1997, Medellín et al. 1998, Collins \& Dubach 2000a, b, 2001, Cortés-Ortiz et al. 2003, Collins 2004) indicando una separación relativamente antigua de estas mastofaunas. Patrones similares se han detectado en plantas (Moretti et al. 1993, Novick et al. 2003), peces dulceacuícolas (Lydeard et al. 1995, Concheiro-Pérez et al. 2007), anfibios (Hillis 1988, Parra-Olea et al. 2004), reptiles (Wüster et al. 2005) y aves (Hackett 1993, Marks et al. 2002). Incluso en algunos trabajos se ha documentado que la Falla PolochicMotagua no solo demarca al grupo Yucatán y Pantanos de Centla* del grupo TehuantepecPanamá*, sino que además muchas distribuciones complementarias se extienden hasta aquí (e.g. Schuster et al. 2003, Liede \& Meave 2004), lo que sugiere que los grupos se han originado por vicarianza. Rogers (2003), señala que las fallas Jocotan-Chamelecon, Polochic y Motagua se desarrollaron en el interior de Guatemala, a lo largo de la última sutura Cretácica del Valle de Motagua, entre los bloques de Chortis y Maya.

No obstante, también se ha propuesto que dichos patrones evidencian una colonización de la península proto-Mesoamericana por la flora de América del Sur antes de la formación del Istmo de Panamá. La estructura de las filogenias, sugieren colonizaciones repetidas hacia Mesoamérica por poblaciones australes. Este modelo implicaría colonización antigua preístmica de tipos más adaptados a la sequía, con una extensión secundaria a través del puente terrestre de tipos adaptados a mayor humedad, posiblemente posterior al Pleistoceno, que poseen el patrón meridional del sur (Hamilton 1989, Dehgan \& Schutzman 1994, Croat 1997, 
Cavers et al. 2003). Cabe resaltar que un aspecto importante de la expansión a Mesoamérica por taxones de América del Sur, son los efectos continentales de la orogenia andina. Este levantamiento precede por mucho el contacto con Mesoamérica y ocurrió hace más de 27 millones de años (m.a.), en la última mitad del Cenozoico. Entre los ocho y diez m.a., la Cordillera Oriental en Colombia y Venezuela aisló con eficacia muchos taxones hacia el norte de los Andes. Subsecuente a ese tiempo, solo ocurrió un movimiento limitado de taxones neotropicales del este, particularmente amazónicos (Rull 1998).

El otro modelo, derivado de análisis del mtDNA de monos aulladores (Cortés-Ortíz et al. 2003) y del resto de la biota, sugieren una dispersión explosiva a través de la región seguida por diferenciación rápida, donde las causas más importantes de especiación señalan hacia el continuo ascenso de las cordilleras del este y occidentales de los Andes, así como de los cambios asociados al hábitat. Éstos incluyen trabajos sobre plantas (Richardson et al. 2001, Novick et al. 2003), artrópodos (Zeh et al. 2003), peces dulceacuícolas (Perdices et al. 2002, 2005, Rican et al. 2008), anfibios (Weigt et al. 2005, Wang et al. 2008), reptiles (Zamudio \& Greene 1997), mamíferos (Collins \& Dubach 2000a, Collins 2004, Larsen et al. 2007), así como loros (Eberhard \& Bermingham 2004). Estas coincidencias parecen indicar que procesos geobióticos comunes han inducido estos patrones; sin embargo, otros estudios han demostrado una escasa diferenciación en las tierras bajas mesoamericanas, además sugieren que la especiación en estas tierras se debe más a dispersión que a vicarianza (Savage 1982, Halffter 1987, Wake et al. 1992, Marshall \& Liebherr 2000, Huidobro et al. 2006), inclusive Köhler (2003) propone solo dos tipos de barreras efectivas para las especies de tierras bajas: los macizos montañosos y áreas de clima inusual. Por lo pronto, puede ser prematuro resumir la historia de esta compleja región en patrones biogeográficos generales, puesto que muchos investigadores apenas se encuentran en etapas preliminares de recopilar información de linajes extensos del Neotrópico.

Reconstrucción de relaciones biogeográficas: Las relaciones históricas entre las áreas de Mesoamérica no están del todo claras, al parecer el grupo de trabajo, la taxonomía empleada y la delimitación de áreas son un factor determinante (Savage 1982, Flores-Villela \& Goyenechea 2001, Groves 2001, Morrone 2005b, Rylands et al. 2005). Sin embargo, la hipótesis en el presente estudio es muy similar a la filogenia del mono araña Ateles (Collins \& Dubach 2000b), donde se sugiere que la Península de Yucatán y los BTP de Guatemala y Honduras son hermanas, que los BTP de Nicaragua y Panamá están estrechamente relacionados y a su vez están asociadas con el clado anterior; además en las hipótesis de las tangaras Ramphocelus (Hackett 1996), 29 especies de aves (Brumfield \& Capparella 1996) y de los peces dulceacuícolas Brycon, Bryconamericus, Eretmobrycon y Cyphocharax (Reeves \& Bermingham 2006), se propone que las Tierras Bajas del Pacífico Sur y del Caribe de Centroamérica son áreas hermanas, que la región de Chocó es el área hermana de las Tierras Bajas de Centroamérica, y las Tierras Bajas del Amazonas es la hermana del clado Centroamérica/Chocó. Este mismo cladograma general de áreas ha sido sugerido a partir de análisis morfológicos (Cracraft \& Prum 1988, Prum 1988).

Las áreas de endemismo obtenidas con PAE y las distribuciones potenciales identificadas nos permitieron construir la historia de la región con base en los patrones de las especies endémicas compartidas (Humphries \& Parenti 1986, Rosen \& Smith 1988, Rosen 1992), aunque también se pueden interpretar en un contexto ecológico para influenciar nuevas hipótesis. En parte, las condiciones ambientales actuales explican la delimitación de las áreas de endemismo. El cambio de clima durante el Pleistoceno y sus efectos en la vegetación de Mesoamérica posiblemente han repercutido en los procesos de especiación y pueden sugerir diversos acontecimientos vicariantes. 
El método empleado, es el propuesto por Morrone (1994) y aunque presenta algunas semejanzas con el PAE formulado por Rosen (1988), ha sido profundamente criticado (Brooks \& van Veller 2003, Santos 2005, Nihei 2006, Santos \& Amorim 2007), e incluso algunos autores no lo consideran un método biogeográfico histórico (Cracraft 1991, Humphries 2000, García-Barros et al. 2002, Brooks \& van Veller 2003, Porzecanski \& Cracraft 2005, Peterson 2008); y Nihei (2006) y Peterson (2008) también le objetan el aplicarlo en áreas delimitadas artificialmente, incompletas o por el empleo de distribuciones parciales que falsean las relaciones obtenidas. No obstante, Morrone (2004a) establece que éste método identifica homología primaria, por ello lo considera como un primer paso en un análisis biogeográfico, reconociendo los componentes que deben ser analizados, además de contrastarlo con hipótesis filogenéticas de algunas especies del área analizada; principalmente porque existe un acuerdo general de que la mejor evidencia de las relaciones entre las áreas, surge a partir de patrones filogenéticos (Nelson \& Platnick 1981). Además el método fue propuesto sin suponer ningún proceso (Rosen 1988, Crisci 2001), aunque la vicarianza sea el mecanismo más común de la especiación (Barraclough \& Vogler 2000). Por último, el presente trabajo se desarrolló en un área natural (sistema cerrado), con la intención de que la mayoría de los linajes fueran de distribución restringida; en el caso contrario, las relaciones no serían evidentes en los resultados, porque algunas especies se extienden hasta áreas excluidas del análisis (Peterson 2008).

Conservación: Myers et al. (2000) consideran que Mesoamérica es uno de los "hotspots" más importantes del mundo. Los "hotspots" en su concepción original son áreas que ofrecen concentraciones importantes de riqueza, endemismo y una pérdida excepcional del hábitat. No obstante, tan solo el $12.6 \%$ de la superficie de Mesoamérica se encuentra dentro de áreas protegidas, y en proporción de superficie protegida por nación, Belice y Costa
Rica encabezan la lista, y aunque la parte de México representa la superficie protegida más grande, equivale a menos del $9 \%$ de su territorio (CONANP 2003). Los recursos encaminados a frenar o revertir los factores de deterioro en Mesoamérica son limitados, a pesar de los esfuerzos realizados por los gobiernos de la región, algunas ONG, así como de Conservation International, World Wildlife Fund, The Nature Conservancy y The Wildlife Conservation Society. Por ello, los fondos obtenidos mediante el ecoturismo son un fuerte incentivo para efectos de conservación, no solo en Costa Rica, sino también en otras partes de la región (Langholz 1999, Langholz et al. 2000).

El futuro del BTP mesoamericano no es prometedor. Aunque algunos de los fragmentos restantes se encuentran legalmente protegidos, la mayoría, al igual que las plantas y animales que habitan en ellos, encaran el riesgo de desaparecer (Pimm et al. 1995, Challenger 1998, Carrillo et al. 2000). Las amenazas resultan a menudo de la demanda incontrolada de recursos y de la fragmentación y transformación del bosque a otro tipo de cobertura vegetal (Carrillo et al. 2000, Cuarón 2000, GalindoGonzález et al. 2000, Medellín et al. 2000). Por lo tanto, el desafío es explorar nuevas estrategias para proteger la vegetación primaria de esta comunidad, dentro y fuera de las reservas, y aprender a utilizar los recursos de manera sustentable, sin enfrentarse con las políticas encaminadas a su conservación. La protección de especies emblemáticas, diversidad, recambio de especies, vulnerabilidad, presencia de especies restringidas o en alguna categoría de conservación, además de los procesos ecológicos y del funcionamiento del paisaje, han sido los principales criterios empleados para elegir áreas a conservar (Arita et al. 1997, Nott \& Pimm 1997, Scott et al. 1999, Eeley et al. 2001, Urquiza-Haas et al. 2011). En el caso de los mamíferos mexicanos, se han desarrollado estrategias encaminadas a la selección de áreas prioritarias a partir de especies protegidas por la normatividad nacional y de distribución restringida (Ceballos 1999, Urquiza-Haas et al. 2011), patrones de riqueza y endemismo 
(Escalante 2003b), así como diversidad beta y complementariedad (Rodríguez et al. 2003). Sin embargo, se ha señalado que existe una disyuntiva en conservación, debido a la baja correspondencia entre áreas de mayor riqueza y alto endemismo, así como elevada concentración de especies en riesgo (Vane-Wright et al. 1991, Ceballos et al. 1998). Por ello, sería importante que las estrategias encaminadas a establecer prioridades de conservación tomen en cuenta el mayor número de criterios posibles, sin hacer a un lado los biogeográficos (Morrone \& Crisci 1992, Grehan 1993, Morrone 1999), y aunque es muy probable que el PAE enmascare regiones importantes con áreas que concentran una elevada riqueza (Trejo-Torres \& Ackerman 2001), los resultados pueden ser muy útiles en la toma de decisiones (Posadas 1996, Posadas \& Miranda-Esquivel 1999), sobre todo porque los patrones de endemismo, pueden proporcionar una clara evidencia de la especificidad del hábitat para la gama de especies presentes (Espadas-Manrique et al. 2003).

\section{AGRADECIMIENTOS}

H.C.O.M. agradece al programa del Posgrado en Ciencias Biológicas, UNAM por permitirme realizar mis estudios de Maestría, y a la beca del Posgrado de Excelencia otorgada por el Consejo Nacional de Ciencia y Tecnología. Así mismo, agradecemos de forma personal a Oscar A. Flores Villela, Víctor Sánchez-Cordero Dávila, David N. Espinosa Organista, Juan J. Morrone y cuatro revisores anónimos por sus particulares puntos de vista $\mathrm{y}$ valiosos comentarios a diversas etapas del manuscrito. A las colecciones científicas que facilitaron la información necesaria: American Museum of Natural History; Bell Museum of Natural History, University of Minnesota; Berkeley, Museum of Vertebrate Zoology, University of California; Burke Memorial Washington State Museum, University of Washington; California Academy of Sciences; Carnegie Museum of Natural History; Comisión Nacional para el Conocimiento y uso de la Biodiversidad; El Colegio de la Frontera
Sur; Escuela Nacional de Ciencias Biológicas, Instituto Politécnico Nacional; Instituto de Biología, Universidad Nacional Autónoma de México; Instituto Nacional de Cultura, Museo de Ciencias Naturales; Louisiana State University, Museum of Natural Science; Los Angeles County Museum of Natural History; Michigan State University Museum; Museo de Historia Natural de El Salvador; Museo de Vertebrados, Universidad de Panamá; Museo de Zoología "Alfonso L. Herrera", Facultad de Ciencias, Universidad Nacional Autónoma de México; Museo de Zoología, Universidad de Costa Rica; Museo Nacional de Costa Rica; Museum of Comparative Zoology, Harvard University; Museum of Natural History, University of Illinois; Museum of Natural History, University of Kansas; Museum of Southwestern Biology, University of New Mexico; Museum of Zoology, University of Michigan; National Museum of Natural History; Natural History Museum of Los Angeles County; Royal Ontario Museum; Sam Noble Oklahoma Museum of Natural History; Texas A\&M University; The Field Museum; The Museum, Texas Tech University; The Science Museum of Minnesota; United States National Museum of Natural History; Universidad Autónoma Metropolitana-Iztapalapa; Utah Museum of Natural History; Yale University Peabody Museum.

\section{RESUMEN}

Este trabajo presenta una propuesta de regionalización biogeográfica de los bosques tropicales perennifolios de Mesoamérica, resultado de un análisis de parsimonia de endemismos (PAE), utilizando modelos de nicho ecológico (GARP) con mamíferos terrestres, usando 41527 registros para las 233 especies de mamíferos reconocidas. La regionalización propuesta muestra que los bosques tropicales perennifolios de Mesoamérica se dividen por el Istmo de Tehuantepec en Oaxaca en: a) un grupo septentrional que comprende la Sierra Madre de Chiapas-Guatemala y la Península de Yucatán, y b) un grupo austral, que contiene la vertiente pacífica hacia el sur incluyendo Centroamérica. Además se encontró congruencia con trabajos filogenéticos, lo que sugiere una historia biogeográfica común.

Palabras clave: mamíferos, Mesoamérica, regionalización, análisis de parsimonia de endemismos, GARP. 


\section{REFERENCIAS}

Allen, J.A. 1904. Mammals from southern Mexico and Central and South America. B. Am. Mus. Nat. Hist. 20: 29-80.

Allen, J.A. 1908. Mammals from Nicaragua. B. Am. Mus. Nat. Hist. 24: 647-699.

Allen, J.A. 1910. Additional mammals from Nicaragua. B. Am. Mus. Nat. Hist. 28: 87-115.

Allen, R.K. 1990. Distribution patterns of North and Central American mayflies (Ephemeroptera), p. 170180. In I.C. Campbell (ed.). Mayflies and Stoneflies. Kluwer, Dordrecht, Países Bajos.

Alroy, J. 2002. How many named species are valid? P. Natl. Acad. Sci. USA 99: 3706-3711.

Anderson, R.P., M. Gómez-Laverde \& A.T. Peterson. 2002. Geographical distributions of spiny pocket mice in South America: insights from predictive models. Global. Ecol. Biogeogr. 11:131-141.

Anderson, R.P., D. Lew \& A.T. Peterson. 2003. Evaluating predictive models of species' distributions: criteria for selecting optimal models. Ecol. Model. 162: 211-232.

Arita, H., F. Figueroa, A, Frish, P. Rodríguez \& K. Santos Del Prado. 1997. Geographical range size and the conservation of Mexican mammals. Conserv. Biol. 11: 92-100.

Audet, D., M.D. Engstrom \& M.B. Fenton. 1993. Morphology, karyology, and echolocation calls of Rhogees$s a$ (Chiroptera: Vespertilionidae) from the Yucatan Peninsula. J. Mammal. 74: 498-502.

Barraclough, T.G. \& A.P. Vogler. 2000. Detecting the geographical pattern of speciation from species-level phylogenies. Am. Nat. 155:419-434.

Barrera, A. 1962. La Península de Yucatán como provincia biótica. Rev. Soc. Mex. Hist. Nat. 23: 71-105.

Barrera, N. \& H. Rodríguez (Coords.). 1993. Desarrollo y medio ambiente en Veracruz: impactos económicos, ecológicos y culturales de la ganadería en Veracruz. Friedrich Ebert, Centro de Investigaciones y Estudios Superiores en Antropología Social e Instituto de Ecología, D.F., México.

Bellemain, E., E. Bermingham \& R.E Ricklefs. 2008. The dynamic evolutionary history of the bananaquit (Coereba flaveola) in the Caribbean revealed by a multigene analysis. Evol. Biol. 8: 240-253.

Bermingham, E. \& P.A. Martin. 1998. Comparative mtDNA phylogeography of neotropical freshwater fishes: testing shared history to infer the evolutionary landscape of lower Central America. Mol. Ecol. 7: 499-517.
Binford, L.C. 1989. A distributional survey of the birds of the Mexican state of Oaxaca. Ornithol. Monogr. 43: $1-418$.

Bisconti, M., W. Landini, G. Bianucci, G. Cantalamessa, G. Carnevale, L. Ragiani \& G. Valleri. 2001. Biogeographic relationships of the Galapagos terrestrial biota: parsimony analyses of endemicity based on reptiles, land birds and Scalesia land plants. J. Biogeogr. 28: 495-510.

Breedlove, D.E. 1973. The phytogeography and vegetation of Chiapas (Mexico), p. 149-165. In A. Graham (ed.). Vegetation and vegetational history of northern Latin America. Elsevier, Amsterdam, Países Bajos.

Brooks, D.R. \& M.G.P. van Veller. 2003. Critique of parsimony analysis of endemicity as a method of historical biogeography. J. Biogeogr. 30: 819-825.

Brooks, T.M., R.A. Mittermeier, C.G. Mittermeier, G.A. da Fonseca, A.B. Rylands, W.R. Konstant, P. Flick, J. Pilgrim, S. Oldfield, G. Magin \& C. Hilton-Taylor. 2002. Habitat loss and extinction in the hotspots of biodiversity. Conserv. Biol. 16: 909-923.

Brown, K.S. Jr. 1982. Paleoecological and regional patterns of evolution in neotropical forest butterflies, p. 255308. In G.T. Prance (ed.). Biological Diversification in the Tropics. Columbia, Nueva York, EE.UU.

Brown, K.S. Jr. 1987a. Biogeography and evolution of Neotropical butterflies, p. 66-104. In T.C. Whitmore \& G.T. Prance (eds.). Biogeography and Quaternary History in Tropical America. Clarendon, Oxford, Reino Unido.

Brown, K.S. Jr. 1987b. Conclusions, synthesis, and alternative hypotheses, p. 175-210. In T.C. Whitmore \& G.T. Prance (eds.). Biogeography and Quaternary History in Tropical America. Clarendon, Oxford, Reino Unido.

Brumfield, R.T. \& A.P. Capparella. 1996. Historical diversification of birds in northwestern South America: a molecular perspective on the role of vicariant events. Evolution 50: 1607-1624.

Burnham, R.J. \& A. Graham. 1999. The history of Neotropical vegetation: new developments and status. Ann. Mo. Bot. Gard. 86: 546-589.

Bush, M.B. 1994. Amazonian speciation: a necessarily complex model. J. Biogeogr. 21: 5-17.

Campbell, J.A. 1999. Distribution patterns of amphibians in Middle America, p. 111-210. In W.E. Duellman (ed.). Patterns of Distribution of Amphibians: A Global Perspective. Johns Hopkins, Baltimore, EE.UU.

Carleton, M.D., O. Sánchez \& G. Urbano-Vidales. 2002. A new species of Habromys (Muroidea: Neotominae) from México, with generic review of species definitions and remarks on diversity patterns among Mesoamerican small mammals restricted to humid montane forests. P. Biol. Soc. Wash. 115: 488-533. 
Carrillo, E., G. Wong \& A.D. Cuarón. 2000. Monitoring mammal populations in Costa Rican protected areas under different hunting restrictions. Conserv. Biol. 14: $1580-1591$.

Castellanos, E., C. Monzón, V. Valencia, L. Delgado, O. Regalado, L. Corral, J. Roldán, J.F. Roldán, G. Pérez, J.P. Noriega, R. Veliz, V.H. Ramos, H. Solís, J.E. Zetina, L. Guerra \& F. Saravia. 2001. Dinámica de la Cobertura Forestal de Guatemala durante los años 1991, 1996 y 2001 y Mapa de Cobertura Forestal 2001. Fase II: Dinámica de la Cobertura Forestal. Universidad del Valle de Guatemala, Instituto Nacional de Bosques y el Consejo Nacional de Áreas Protegidas, Guatemala, Guatemala.

Cavers, S., C. Navarro \& A.J. Lowe. 2003. Chloroplast DNA phylogeography reveals colonization history of a Neotropical tree, Cedrela odorata L., in Mesoamerica. Mol. Ecol. 12: 1451-1460.

Ceballos, G. 1999. Áreas prioritarias para la conservación de los mamíferos de México. Biodiversitas 27: 1-8.

Ceballos, G. \& D. Navarro. 1991. Diversity and conservation of Mexican mammals, p 167-188. In M.A. Mares \& D. Schmidly (eds.). Latin American mammalogy: history, biodiversity and conservation. Oklahoma Museum of National History, Norman, Oklahoma.

Ceballos, G. \& G. Oliva. 2005. Los Mamíferos Silvestres de México. Comisión Nacional para el Conocimiento y Uso de la Biodiversidad (CONABIO), Fondo de Cultura Económica, D.F., México.

Ceballos, G., J. Arroyo-Cabrales \& R.A. Medellín. 2002. The mammals of Mexico: composition, distribution, and conservation. Occas. Papers Mus. Texas Tech. Univ. 218: 1-27.

Ceballos, G., P. Rodríguez \& R.A. Medellín. 1998. Assessing conservation priorities in megadiverse Mexico: mammalian diversity, endemicity, and endangerment. Ecol. Appl. 8: 8-17.

Ceballos, G., J. Arroyo-Cabrales, R.A. Medellín \& Y. Domínguez-Castellanos. 2005. Lista actualizada de los mamíferos de México. Rev. Mex. Mastozoo. 9: 21-71.

Chakrabarty, P. 2006. Systematics and historical biogeography of Greater Antillean Cichlidae. Mol. Phylogenet. Evol. 39: 619-627.

Challenger, A. 1998. Utilización y conservación de los ecosistemas terrestres de México: pasado, presente y futuro. Comisión Nacional para el Conocimiento y Uso de la Biodiversidad (CONABIO), Instituto de Biología de la Universidad Nacional Autónoma de México, Sierra Madre, D.F., México.

Chiappy-Jones, C., V. Rico-Gray, L. Gama \& L. Giddings. 2001. Floristic affinities between the Yucatan Peninsula and some karstic areas of Cuba. J. Biogeogr. 28: 535-542.
Colinvaux, P.A. 1996. Quatenary environmental history and forest diversity in the Neotropics, p. 359-406. In J.B.C. Jackson, A.F. Budd \& A.G. Coates (eds.). Evolution and Environment in Tropical America. University of Chicago, Chicago, EE.UU.

Collins, A.C. 2004. Atelinae phylogenetic relationships: The trichotomy revived? Am. J. Phys. Anthropol. 124: 285-296.

Collins, A.C. \& J.M. Dubach. 2000a. Phylogenetic relationships of spider monkeys (Ateles) based on mitochondrial DNA variation. Int. J. Primatol. 21: 381-420.

Collins, A.C. \& J.M. Dubach. 2000b. Biogeographic and ecological forces responsible for speciation in Ateles. Int. J. Primatol. 21: 421-444.

Collins, A.C. \& J.M. Dubach. 2001. Nuclear DNA variation in spider monkeys (Ateles). Mol. Phylogenet. Evol. 19: 67-75.

Concheiro-Pérez, G.A., O. Rican, G. Ortíz, E. Bermingham, I. Doadrio \& R. Zardoya. 2007. Phylogeny and biogeography of 91 species of heroine cichlids (Teleostei: Cichlidae) based on sequences of the cytochrome b gene. Mol. Phylogenet. Evol. 43: 91-110.

CONANP (Comisión Nacional de Áreas Naturales Protegidas). 2003. http://www.conanp.gob.mx.

Contreras-Medina, R. \& I. Luna. 2007. Species richness, endemism and conservation of Mexican gymnosperms. Biodivers. Conserv. 16: 1803-1821.

Cortés-Ortiz, L., E. Bermingham, C. Rico, E. RodríguezLuna, I. Sampaio \& M. Ruiz-García. 2003. Molecular systematics and biogeography of the Neotropical monkey genus, Alouatta. Mol. Phylogenet. Evol. 26: $64-81$.

Cracraft, J., 1985. Historical biogeography and patterns of diversification within the South American areas of endemism, p. 49-84. In P.A. Buckley, M.S. Foster, E.S. Morton, R.S. Ridgely \& F.G. Buckley (eds.). Neotropical Ornithology, Ornithological Monographs, 36. American Ornithology Union, Washington, D.C., EE.UU.

Cracraft, J. 1991. Patterns of diversification within continental biotas: hierarchical congruence among the areas of endemism of Australian vertebrates. Aust. Syst. Bot. 4: 211-227.

Cracraft, J. \& R.O. Prum. 1988. Patterns and processes of diversification: speciation and historical congruence in some Neotropical birds. Evolution 42: 603-620.

Crisci, J.V. 2001. The voice of historical biogeography. J. Biogeogr. 28: 157-168.

Croat, T.B. 1997. A Revision of Philodendron subgenus Philodendron (Araceae) for Mexico and Central America. Ann. Mo. Bot. Gard. 3: 311-704.

Croizat, L. 1976. Biogeografía analítica y sintética ("panbiogeografía") de las Américas. Biblioteca de la 
Academia de Ciencias Físicas, Matemáticas y Naturales, Vols. I y II. Caracas, Venezuela.

Cuarón, A.D. 2000. Effects of land-cover changes on mammals in a Neotropical region: a modeling approach. Conserv. Biol. 14: 1676-1692.

Dehgan, B. \& B. Schutzman. 1994. Contributions toward a monograph of Neotropical Jatropha: phenetic and phylogenetic analyses. Ann. Mo. Bot. Gard. 2: 349-367.

del Hoyo, J., A. Elliott \& J. Sargatal. 1992. Handbook of the birds of the world. Volume 1: Ostrich to ducks. Lynx, Barcelona, España.

Díaz-Gallegos, J.R. \& J.F. Mas. 2008. Deforestation monitoring and its accuracy assessment: the case of Southeast Mexico, p. 109-126. In Progress in Deforestation Studies. Nova, Nueva York, EE.UU.

Dirzo, R. \& A. Miranda. 1991. El límite boreal de la selva tropical húmeda en el Continente Americano: contracción de la vegetación y solución de una controversia. Interciencia 5: 240-247.

Duellman, W.E. 1966. The Central American herpetofauna: an ecological perspective. Copeia 4: 700-719.

Duellman, W.E. 2001. The Hylid frogs of Middle America. Society for the Study of Amphibians and Reptiles, Natural History Museum of the University of Kansas. Vols. 1 y 2. Nueva York, EE.UU.

Durán, R. \& J. Olmsted. 1987. Listado florístico de la Reserva de Sian Ka'an. Amigos de Sian Ka'an. Puerto Morelos, Q. Roo, México.

Durán, R., J.C. Trejo-Torres \& G. Ibarra Manríquez. 1998. Endemic phytotaxa of the peninsula of Yucatan. Harvard Pap. Bot. 3: 263-314.

Eberhard, J.R. \& E. Bermingham. 2004, Phylogeny and biogeography of the Amazona ochrocephala (Aves: Psittacidae) complex. Auk 121: 318-332.

Eeley, H.A.C., M.J. Lawes \& B. Reyers. 2001. Priority areas for the conservation of sub-tropical indigenous forest in southern Africa: a case study from KwazuluNatal. Biodivers. Conserv. 10: 1221-1246.

Eisenberg, J.F. 1990. Neotropical mammal communities, p. 358-368. In A.H. Gentry (ed.). Four Neotropical Rainforest. Yale University, New Haven, EE.UU.

Elith, J., C.H. Graham, R.P. Anderson, M. Dudik, S. Ferrier, A. Guisan, R.J. Hijmans, F. Huettmann, J.R. Leathwick, A. Lehmann, J. Li, L.G. Lohmann, B.A. Loiselle, G. Manion, C. Moritz, M. Nakamura, Y. Nakazawa, J.McC. Overton, A.T. Peterson, S.J. Phillips, K.S. Richardson, R. Scachetti-Pereira, R.E. Schapire, J. Soberón, S. Williams, M.S. Wisz \& N.E. Zimmermann. 2006. Novel methods improve prediction of species' distributions from occurrence data. Ecography 29: 129-151.
Endler, J.A. 1982. Pleistocene forest refuges: Fact or fancy? p. 641-656. In G.T. Prance (ed.). Biological Diversification in the Tropics. Columbia University, Nueva York, EE.UU.

Engel, S.R., K.M. Hogan, J.F. Taylor \& S.K. Davis. 1998. Molecular systematics and paleobiogeography of the South American sigmodontine rodents. Mol. Biol. Evol. 15: 35-49.

Engstrom, M.D., H.H. Genoways \& P.K. Tucker. 1987. Morphological variation, karyology, and systematic relationships of Heteromys gaumeri (Rodentia: Heteromyidae), p. 289-303. In B.D. Patterson \& R.M. Timm (eds.). Studies in neotropical mammalogy: essays in honor of Philip Hershkovitz. Fieldiana Zool. 39: $1-506$.

Escalante, T. 2011. De cómo el análisis de parsimonia de endemismos (PAE) tampoco explica la selección natural. Rev. Mex. Biod. 82: 1057-1059.

Escalante, T. \& J.J. Morrone. 2003. ¿Para qué sirve el Análisis de Parsimonia de Endemismos? p. 167-172. In J. Llorente-Bousquets \& J.J. Morrone (eds.). Una Perspectiva Latinoamericana de la Biogeografía. Facultad de Ciencias, Universidad Nacional Autónoma de México, D.F., México.

Escalante, T., D. Espinosa \& J.J. Morrone. 2002. Patrones de distribución geográfica de los mamíferos terrestres de México. Acta Zool. Mex. 87: 47-65.

Escalante, T., D. Espinosa \& J.J. Morrone. 2003a. Patterns of endemicity of terrestrial mammals within Mexican ecoregions. Southwest. Nat. 48: 563-578.

Escalante, T., D. Espinosa \& J.J. Morrone. 2003b. Using Parsimony Analysis of endemism to analyze the distribution of Mexican land mammals. Southwest. Nat. 48: 563-578.

Escalante, T., V. Sánchez-Cordero, J.J. Morrone \& M. Linaje. 2007. Areas of endemism of Mexican terrestrial mammals: A case study using species' ecological niche modeling, Parsimony Analysis of Endemicity and Goloboff fit. Interciencia 32: 151-159.

Espadas-Manrique, C., R. Durán \& J. Argáez. 2003. Phytogeographic analysis of taxa endemic to the Yucatán Peninsula using geographic information systems, the domain heuristic method and parsimony analysis of endemicity. Div. Distr. 9: 313-330.

Estrada-Loera, E. 1991. Phytogeographic Relationships of the Yucatan Peninsula. J. Biogeogr. 18: 687-697.

Ewell, P.T. \& T.T. Poleman. 1980. Uxpanapa: reacomodo y desarrollo agrícola en el trópico mexicano. Instituto Nacional de Investigación sobre Recursos Bióticos, México.

FAO. 2002. State of the World Forest 2001. FAO, Roma, Italia.

Flores-Villela, O. \& I. Goyenechea. 2001. A comparison of hypotheses of historical area relationships for Mexico 
and Central America, or in search for the lost pattern, p. 171-181. In J. Johnson, R.G. Webb \& O. FloresVillela (eds.). Mesoamerican Herpetology: systematics, zoogeography, and conservation. Centennial Museum, Special Publication, University of Texas, El Paso, Texas, EE.UU.

Flores-Villela, O. \& A. Navarro. 1993. Un análisis de los vertebrados terrestres endémicos de Mesoamérica en México. Rev. Soc. Mex. Hist. Nat. 44: 387-395.

Galindo-González, J., S. Guevara \& V.J. Sosa. 2000. Batand bird-generated seed rains at isolated trees in pastures in a tropical rainforest. Conserv. Biol. 14: 1693-1703.

García, A. 2006. Using ecological niche modelling to identify diversity hotspots for the herpetofauna of Pacific lowlands and adjacent interior valleys on México. Biol. Conserv. 130: 25-46.

García-Barros, E., P. Gurrea, M.J. Luciáñez, J.M. Cano, M.L. Munguira, J.C. Moreno, H. Sainz, M.J. Sanz \& J.C. Simón. 2002. Parsimony analysis of endemicity and its application to animal and plant geographical distributions in the Ibero-Balearic region (western Mediterranean). J. Biogeogr. 29: 109-124.

Gaston, K.G. \& L.A. Mound. 1993. Taxonomy, hypothesis and the biodiversity crisis. Philos. T. Roy. Soc. B 251: 139-142.

Genoways, H.H. \& R.J. Baker. 1996. A new species of the genus Rhogeessa, with comments on geographic distribution and speciation in the genus, p. 83-87. In H.H. Genoways \& R.J. Baker (eds.). Contributions in mammalogy: A memorial volume in honor of $\mathrm{J}$. Knox Jones, Jr. Museum of Texas Tech University, Lubbock, Texas.

Gentry, A.H. 1982. Neotropical floristic diversity: phytogeographical connections between Central and South America, Pleistocene climatic fluctuations, or an accident of the Andean orogeny? Ann. Mo. Bot. Gard. 69: 557-593.

Gentry, A.H. 1992. Distributional patterns of Central America and West Indian Bignoniaceae, p. 111-125. In S.P. Darwin \& A.L. Welden (eds.). Biogeography: proceedings of a symposium, Mérida, Yucatán, México, October 26-30, 1984. Tulane studies in zoology and botany. Supplementary publication 1 .

Goldman, E.A. \& R.T. Moore. 1946. Biotic provinces of Mexico. J. Mammal. 26: 347-360.

Goloboff, P. 1994. NONA: a tree searching program. Program and documentation. Available at ftp.unt.edu.ar/ pub/parsimony

Gómez-Pompa, A. 1985. Los recursos bióticos de México (Reflexiones). Instituto Nacional de Investigación sobre Recursos Bióticos, Alhambra, D.F., México.

Good, R. 1974. The geography of the flowering plants. Longman Group Limited, Londres.
Goodwin, G.G. 1942. Mammals of Honduras. B. Am. Mus. Nat. Hist. 74: 107-195.

Goodwin, G.G. 1946. Mammals of Costa Rica. B. Am. Mus. Nat. Hist. 87: 271-474.

Goodwin, G.G. 1955. Mammals from Guatemala, with the Description of a New Little Brown Bat. Am. Mus. Nov. 1744: 1-5.

Goodwin, G.G. 1969. Mammals from the State of Oaxaca, Mexico in the American Museum of the Natural History. B. Am. Mus. Nat. Hist. 141: 1-270.

Grehan, J.R. 1993. Conservation biogeography and the biodiversity crisis: A global problem in space/time. Biodivers. Lett. 1: 134-140.

Groves, C. 2001. Primate Taxonomy. Smithsonian Institution. Washington, D.C., EE.UU.

Guisan, A. \& N.E. Zimmermann. 2000. Predictive habitat distribution models in ecology. Ecol. Model. 135: 147-186.

Hackett, S.J. 1993. Phylogenetic and biogeographic relationships in the Neotropical genus Gymnopithys (Formicariidae). Wilson Bull. 105: 301-315.

Hackett, S.J. 1996. Molecular phylogenetics and biogeography of tanagers in the genus Ramphocelus (Aves). Mol. Phylogenet. Evol. 5: 368-382.

Haffer, J. 1982. General aspects of the Refuge Theory, p. 6-24. In G.T. Prance (ed.). Biological Diversification in the Tropics. Columbia University, Nueva York, EE.UU.

Haffer, J. 1987. Biogeography of neotropical birds, p. 105150. In T.C. Whitmore \& G.T. Prance (eds.). Biogeography and Quaternary History in Tropical America. Clarendon, Oxford, Reino Unido.

Halffter, G. 1987. Biogeography of the montane entomofauna of Mexico and Central America. Annu. Rev. Entomol. 32: 95-114.

Hall, E.R. 1981. The Mammals of North America. Vols. I y II. Wiley, Nueva York, EE.UU.

Hamilton, C.W. 1989. A revision of Mesoamerican Psychotria subgenus Psychotria (Rubiaceae). Ann. Mo. Bot. Gard. 76: 67-111.

Hawkins, B.A., J.A.F. Diniz-Filho, C.A. Jaramillo \& S.A. Soeller. 2006. Post-Eocene climate change, niche conservatism, and the latitudinal diversity gradient of New World birds. J. Biogeogr. 33: 770-780.

Hernández, P.A., C.H. Graham, L.L. Master \& D.L. Albert. 2006. The effect of sample size and species characteristics on performance of different species distribution modeling methods. Ecography 29: 773-785.

Hijmans, R.J., S.E. Cameron, J.L. Parra, P.G. Jones \& A. Jarvis. 2005. Very high resolution interpolated climate surfaces for global land areas. Int. J. Climatol. 25: 1965-1978. 
Hillis, D.M. 1988. Systematics of the Rana pipiens complex: puzzle and paradigm. Annu. Rev. Ecol. Syst. 19: 39-63.

Hoffman, F.G. \& R.J. Baker. 2003, Comparative phylogeography of short-tailed bats (Carollia: Phyllostomidae). Mol. Ecol. 12: 3403-3414.

Holdridge, L.E. 1957. The vegetation of mainland Middle America. P. VIII Pac. Sci. Congr. 1953: 148-161.

Holdridge, L.E., W.C. Grenke, W.H. Hatheway, T. Liang \& J.A. Tosi. 1971. Forest environments in tropical life zones: a pilot study. Pergamon, Oxford, Reino Unido.

Huidobro, L., J.J. Morrone, J.L. Villalobos \& F. Álvarez. 2006. Distributional patterns of freshwater taxa (fishes, crustaceans and plants) from the Mexican Transition Zone. J. Biogeogr. 33: 731-741.

Humphries, C.J. 2000. Form, space and time: Which comes first? J. Biogeogr. 27: 11-15.

Humphries, C.J. \& L.R. Parenti. 1986. Cladistic biogeography. Oxford monographs on biogeography No. 2. Clarendon, Oxford, Reino Unido.

Hutchinson, G.E. 1957. Concluding remarks. Cold Sprig Harbor Symposia on Quantitative Biology. Yale University, New Haven, EE.UU.

Ibarra-Manríquez, G., J.L. Villaseñor, R. Durán \& J. Meave. 2002. Biogeographical analysis of the tree flora of the Yucatán peninsula. J. Biogeogr. 29: 17-29.

Illoldi-Rangel, P. \& T. Escalante. 2008. De los modelos de nicho ecológico a las áreas de distribución geográfica. Biogeografía 3: 7-12.

Illoldi-Rangel, P., V. Sánchez-Cordero \& A.T. Peterson. 2004. Predicting distributions of mexican mammals using ecological niche modeling. J. Mammal. 85: 658-662.

INEGI (Instituto Nacional de Estadística, Geografía e Informática). 1982. Carta de México Topográfica 1:250 000. INEGI, D.F., México.

Kinzey, W.G. 1997. New World primates: ecology, evolution and behavior. Aldine de Gruyte, Nueva York, EE.UU.

Köhler, G. 2003. Reptiles of Central America. Herpeton, Germany.

Krishtalka, L. \& P.S. Humphrey. 2000. Can natural history museums capture the future? Bioscience 50: 611-617.

Kruckeberg, A.R. \& D. Rabinowitz. 1985. Biological aspects of endemism in higher plants. Annu. Rev. Ecol. Syst. 16: 447-479.

Langholz, J. 1999. Exploring the effects of alternative income opportunities on rainforest use: insights from Guatemala's Maya Biosphere Reserve. Soc. Natur. Resour. 12: 139-149.

Langholz, J., J. Lassoie \& J. Schelhas. 2000. Incentives for Biological Conservation: Costa Rica's
Private Wildlife Refuge Program. Conserv. Biol. 14: 1735-1743.

Larsen, P.A., R.H. Steven, M.C. Bozeman, S.C. Pedersen, H.H. Genoways, C.J. Phillips, D.E. Pumo \& R.J. Baker. 2007. Phylogenetics and Phylogeography of the Artibeus jamaicensis complex based on cytochrome- $b$ DNA sequences. J. Mammal. 88: 712-727.

Leopold, A.S. 1950. Vegetation zones of Mexico. Ecology 31: 507-518.

Liede, S. \& U. Meave. 2004. Revisión de Metastelma (Apocynaceae-Asclepiadoideae) in southwestern North America and Central America. Ann. Mo. Bot. Gard. 91: 31-86.

Little, D.P. \& D.S. Barrington. 2003. Major evolutionary events in the origin and diversification of the fern genus Polystichum (Dryopteridaceae). Am. J. Bot. 90: 508-514.

Lobo, J.M., A. Baselga, J. Hortal, A. Jiménez-Valverde \& J.F. Gómez. 2007. How does the knowledge about the spatial distribution of Iberian dung beetle species accumulate over time? Div. Distr. 13: 772-780.

Lot, A. \& A. Novelo. 1992. Afinidades florísticas de las monocotiledóneas acuáticas mesoamericanas, p. 147153. In S.P. Darwin \& A.L. Welden (eds.). Biogeography of Mesoamerica: proceedings of a symposium, Mérida, Yucatán, México, October 26-30, 1984. Tulane studies in zoology and botany. Supplementary publication 1 .

Lovette, I.J. \& E. Bermingham. 1999. Explosive speciation in the New World Dendroica warblers. P. Roy. Soc. Lond. B Bio. 266: 1629-1636.

Lovette, I.J. \& D.R. Rubenstein. 2007. A comprehensive molecular phylogeny of the starlings (Aves: Sturnidae) and mockingbirds (Aves: Mimidae): Congruent mtDNA and nuclear trees for a cosmopolitan avian radiation. Mol. Phylogenet. Evol. 44: 1031-1056.

Luna-Vega, I. \& J. Llorente. 1993. Historia Natural del Parque Ecológico Estatal Omiltemi, Chilpancingo, Guerrero, México. CONABIO-UNAM, México D.F., México.

Luna, I. \& R. Contreras-Medina. 2010. Plant biodiversity hotspots and biogeographic methods, p. 181-191. In V. Rescigno \& S. Maletta (eds.). Biodiversity hotspots, Nova-Science Publishers, Nueva York, EE.UU.

Luna, I., O. Alcántara, D. Espinosa \& J.J. Morrone. 1999. Historical relationships of the Mexican clound forests: A preliminary vicariance model applying Parsimony Analysis of Endimicity to vascular planta taxa. J. Biogeogr. 26: 1299-1305.

Lundell, C.L. 1937. The Vegetation of Peten. Studies of Mexican and Central American Plants I. Carnegie Institution Pub. 478 Vol.9, Washington, D.C., EE.UU.

Lundell, C.L. 1942. The vegetation and natural resources of British Honduras. Chronica Bot. 7: 169-171. 
Lydeard, C., M.C. Wooten \& A. Meyer. 1995. Molecules, morphology, and area cladograms: a cladistic and biogeographic analysis of Gambusia (Teleostei: Poeciliidae). Syst. Biol. 44: 221-236.

Madeiros, M.A., R.M.S. Barros, J.C. Pieczarka, C.Y. Nagamachi, M. Ponsa, M. Garcia, F. Garcia \& J. Egozcue. 1997. Radiation and speciation of spider monkeys, genus Ateles, from the cytogenetic viewpoint. Am. J. Primatol. 42: 167-178.

March, I. \& J.M. Aranda. 1992. Mamíferos de la Selva Lacandona, p. 201-220. In M.A. Vázquez \& M.A. Ramos (eds.). Reserva de la Biósfera Montes Azules, selva Lacandona: investigación para su conservación. Publicaciones Especiales, Ecósfera, San Cristóbal de las Casas, Chiapas, México.

Marks, B.D., S.J. Hackett \& A.P. Capparella. 2002. Historical relationships among Neotropical lowland forest areas of endemism as determined by mitochondrial DNA sequence variation within the Wedge-billed Woodcreeper (Aves: Dendrocolaptidae: Glyphorynchus spirurus). Mol. Phylogenet. Evol. 24: 153-167.

Marshall, C.J. \& Liebherr, J.K. 2000. Cladistic biogeography of the Mexican transition zone. J. Biogeogr. 27: 203-216.

Martínez-Meyer, E., A.T. Peterson \& A.G. Navarro. 2004. Evolution of seasonal ecological niches in the Passerina buntings (Aves: Cardinalidae). P. Roy. Soc. Lond. B Bio. 271: 1151-1157.

McCafferty, W.P. \& R.D. Waltz. 1990. Revisionary synopsis of the Baetidae (Ephemeroptera) of North and Middle America. T. Am. Entomol. Soc. 116: 769-799.

McCafferty, W.P., R.W. Flowers \& R.D. Waltz. 1992. The biogeography of Mesoamerican mayflies, p. 173-193. In S.P. Darwin \& A.L. Welden (eds.). Biogeography of Mesoamerica: proceedings of a symposium, Mérida, Yucatán, México, October 26-30, 1984. Tulane studies in zoology and botany. Supplementary publication 1.

McCarthy, T.J. \& S.G. Pérez. 2006. Land and freshwater mammals of Guatemala: faunal documentation and diversity, p. 625-674. In E.B. Cano (ed.). Biodiversidad de Guatemala. Universidad del Valle de Guatemala, Guatemala, Guatemala.

Medellín, R.A. 1991. La fauna: diversidad de los vertebrados, p. 75-109. In P. Robles Gil (ed.). Lacandonia, el último refugio. Universidad Nacional Autónoma de México, Sierra Madre, D.F., México.

Medellín, R.A., A.L. Gardner \& J.M. Aranda. 1998. The taxonomic status of the Yucatán brown brocket, Mazama pandora (Mammalia: Cervidae). P. Biol. Soc. Wash. 111: 1-14.

Medellín, R.A., M. Equihua \& M.A. Amin. 2000. Bat diversity and abundance as indicators of disturbance in Neotropical rainforests. Conserv. Biol. 14: 1666-1675.

Miller, R.R. 1966. Geographical distribution of Central American freshwater fishes. Copeia 4: 773-802.

Miranda, F. 1958. Estudios acerca de la vegetación, p. 213-271. In E. Beltrán (ed.). Los recursos naturales del sureste y su aprovechamiento. Vol. II. México. Instituto Mexicano de Recursos Naturales Renovables, D.F., México.

Miranda, F. \& E. Hernández X. 1963. Los tipos de vegetación de México y su clasificación. Bol. Soc. Bot. Mex. 28: 29-179.

Mittermeier, R.A. 1988. Primate diversity and the tropical forest: case studies from Brazil and Madagascar and the importance of the megadiversity countries, p. 145-154. In E.O. Wilson (ed.). Biodiversity. National Academy, Washington D.C., EE.UU.

Morain, S.A. 1984. Systematic and regional biogeography. Van Nostrand Reinhold Company, Nueva York, EE.UU.

Moretti, A., P. Caputo, S. Cozzolino, P. de Luca, L. Gaudio, G. Siniscalco Gigliano \& D.W. Stevenson. 1993. A Phylogenetic Analysis of Dioon (Zamiaceae). Am. J. Bot. 80: 204-214.

Morón, M.A. 1992. Análisis Biogeográfico preliminar de Plusiotis burmeister (Coleoptera, Melolonthidae, Rutelinae), p. 235-242. In S.P. Darwin \& A.L. Welden (eds.). Biogeography of Mesoamerica: proceedings of a symposium, Mérida, Yucatán, México, October 26-30, 1984. Tulane studies in zoology and botany. Supplementary publication 1 .

Morrone, J.J. 1994. On the identification of areas of endemism. Syst. Biol. 43: 438-441.

Morrone, J.J. 1999. How can biogeography and cladistics interact for the selection of areas for biodiversity conservation? A view from Andean weevils (Coleoptera: Curculionidae). Biogeographica 75: 89-96.

Morrone, J.J. 2001a. Biogeografía de América Latina y el Caribe. M\&T-Manuales \& Tesis SEA, vol. 3, Zaragoza, España.

Morrone, J.J. 2001b. The Neotropical weevil genus Entimus (Coleoptera: Curculionidae: Entiminae): Cladistics, biogeography, and modes of speciation. Coleopts. Bull. 56: 501-513.

Morrone, J.J. 2004a. Homología biogeográfica. Las coordenadas espaciales de la vida. Cuadernos 37. Instituto de Biología - Universidad Nacional Autónoma de México, México.

Morrone, J.J. 2004b. Panbiogeografía, componentes bióticos y zonas de transición. Coleopts. Bull. 48: 149-162.

Morrone, J.J. 2005a. Cladistic biogeography: identity and place. J. Biogeogr. 32: 1281-1284. 
Morrone, J.J. 2005b. Hacia una síntesis biogeográfica de México. Rev. Mex. Biodiv. 76: 207-252.

Morrone, J.J. \& J.V. Crisci. 1992. Aplicación de elementos filogenéticos y panbiogeográficos en la conservación de la diversidad biológica. Evol. Biol. 6: 53-66.

Morrone, J.J. \& J.V. Crisci. 1995. Historical biogeography: introduction to methods. Annu. Rev. Ecol. Syst. 26: 373-401.

Morrone, J.J. \& T. Escalante. 2002. Parsimony analysis of endemicity (PAE) of Mexican terrestrial mammals at different area units: when size matters. J. Biogeogr. 29: 1095-1104.

Morrone, J.J. \& J. Márquez. 2001. Halffter's Mexican Transition Zone, beetle generalised tracks, and geographical homology. J. Biogeogr. 28: 635-650.

Morrone, J.J., J. Llorente-Bousquets \& D. EspinosaOrganista. 2002. Mexican biogeographic provinces: Preliminary scheme, general characterizations, and synonymies. Acta Zool. Mex. 85: 83-108.

Mulcahy, D.G., B.H. Morrill \& J.R.M. III. 2006. Historical biogeography of lowland species of toads (Bufo) across the Trans-Mexican Neovolcanic Belt and the Isthmus of Tehuantepec. J. Biogeogr. 33: 1889-1904.

Müller, D., J. Royer, S. Cande, W. Roest \& S. Maschenkov. 1999. New constraints on the Late Cretaceous/Tertiary plate tectonic evolution of the Caribbean, p. 33-59. In P. Mann (ed.). Caribbean basins: Sedimentary Basins of the World. Elsevier Science, Amsterdam, Países Bajos.

Myers, N., R.A. Mittermeier, C.G. Mittermeier, G.A.B. da Fonseca \& J. Kent. 2000. Biodiversity hotspots for conservation priorities. Nature 403: 853-858.

Nelson, G.J. \& N.I. Platnick. 1981. Systematics and biogeography: cladistics and vicariance. Columbia University, Nueva York, EE.UU.

Nihei, S.S. 2006. Misconceptions about parsimony analysis of endemicity. J. Biogeogr. 33: 2099-2106.

Nixon, K. 1999. The parsimony ratchet, a new method for rapid parsimony analysis. Cladistics 15: 407-414.

Nixon, K. 2000. WinClada, ver.0.9.99. Published by the author. Ithaca, Nueva York, EE.UU.

Nott, M.P. \& S.L. Pimm. 1997. The evaluation of biodiversity as a target for conservation, p. 125-135. In S.T.A. Pickett, R.S. Ostfeld, M. Shachack \& G.E. Likens (eds.). The ecological basis of conservation. Chapman y Hall, Nueva York, EE.UU.

Novick, R.R., C.W. Dick, M.R. Lemes, C. Navarro, A. Caccone \& E. Bermingham. 2003. Genetic structure of Mesoamerican populations of Big-leaf mahogany (Swietenia macrophylla) inferred from microsatellite analysis. Mol. Ecol. 12: 2885-2893.

Olson, D.M., E. Dinerstein, E.D. Wikramanayake, N.D. Burgess, G.V.N. Powell, E.C. Underwood, J.A.
D'Amico, I. Itoua, H.E. Strand, J.C. Morrison, C.J. Loucks, T.F. Allnutt, T.H. Ricketts, Y. Kura, J.F. Lamoreux, W.W. Wettengel, P. Hedao \& K.R. Kassem. 2001 Terrestrial ecoregions of the World: a new map of life on earth. BioScience 51: 933-938.

Ortega-Gutiérrez, F., R.L. Sedlock \& R.C. Speed. 2000. Evolución tectónica de México durante el Fanerozoico, p. 3-59. In J. Llorente, E. González \& N. Papavero (eds.). Biodiversidad taxonomía y biogeografía de artrópodos de México: Hacia una síntesis de su conocimiento, Volumen 2, UNAM-CONABIO, D.F., México.

Overton, L.C. \& D.D. Rhoads. 2006. Molecular phylogenetic relationships of Xiphidiopicus percussus, Melanerpes, and Sphyrapicus (Aves: Picidae) based on cytochrome b sequence. Mol. Phylogenet. Evol. 41: 288-294.

Palacio-Prieto, J.L., G. Bocco, A. Velázquez, J.F. Mas, T.F. Takaki, A. Victoria, L. Luna-González, G. Gómez-Rodríguez, J. López-García, M. Palma-M., I. Trejo-Vázquez, A. Peralta-H., J. Prado-Molina, A. Rodríguez-Aguilar, R. Mayorga-Saucedo \& F. González-M. 2000. La condición actual de los recursos naturales en México: resultados del Inventario Forestal Nacional 2000. Invest. Geog. Bol. Inst. Geog. UNAM 43: 183-203.

Parra-Olea, G., M. García-París \& D.B. Wake. 2004 Molecular diversification of salamanders of the tropical American genus Bolitoglossa (Caudata: Plethodontidae) and its evolutionary and biogeographical implications. Biol. J. Linn. Soc. 81: 325-346.

Patten, M.A. \& B.D. Smith-Patten. 2008. Biogeographical boundaries and Monmonier's algorithm: a case study in the northern Neotropics. J. Biogeogr. 35: 407-416.

Patton, J.L. \& M.F. Smith. 1992. MtDNA phylogeny of Andean mice: a test of diversification across ecological gradients. Evolution 46: 174-183.

Paz-Quevedo, O.W., L.E. Girón, G.M. Rivera, C.E. Dueñas, L.A. Martínez, M.F. Córdova \& C.E. Martínez. 2003. Mamíferos, p. 97-103. In O. Flores-Villela, A. Handal \& L. Ochoa (eds.). Diagnóstico de la Diversidad Biológica de El Salvador. Universidad de El Salvador, Benemérita Universidad Autónoma de Puebla, Universidad Autónoma del Estado de Hidalgo, Universidad Autónoma del Estado de Morelos, Red Mesoamericana de Recursos Bióticos, D.F., México.

Perdices, A., I. Doadrio \& E. Bermingham. 2005. Evolutionary history of the synbranchid eels (Teleostei: Synbranchidae) in Central America and the Caribbean islands inferred from their molecular phylogeny. Mol. Phylogenet. Evol. 37: 460-473.

Perdices, A., E. Bermingham, A. Montilla \& I. Doadrio. 2002. Evolutionary history of the genus Rhamdia (Teleostei: Pimelodidae) in Central America. Mol. Phylogenet. Evol. 25: 172-189. 
Peterson, A.T. 2001. Predicting species geographic distribution based on ecological niche modelling. Condor 103: 599-605.

Peterson, A.T. 2008. Parsimony analysis of endemism and studies of Mexican biogeography. Rev. Mex. Biodiv. 79: $541-542$.

Peterson, A.T. \& K.P. Cohoon. 1999. Sensitivity of distributional prediction algorithms to geographic data completeness. Ecol. Model. 17: 159-164.

Peterson, A.T., L.G. Ball \& K.P. Cohoon. 2002. Predicting distributions of Mexican birds using ecological niche modelling methods. Ibis 144: 27-32.

Peterson, A.T., A.G. Navarro-Sigüenza \& H. Benítez-Díaz. 1998. The need for continued scientific collecting; a geographic analysis of Mexican bird specimens. Ibis 140: 288-294.

Peterson, A.T., M. Papeş \& M. Eaton. 2007. Transferability and model evaluation in ecological niche modeling: a comparison of GARP and Maxent. Ecography 30: 550-560.

Peterson, A.T., M. Papeş \& J. Soberon. 2008. Rethinking receiver operating characteristic analysis applications in ecological niche modeling. Ecol. Mod. 213: 63-72.

Peterson, A.T., J. Soberón \& V. Sánchez-Cordero. 1999. Conservatism of ecological niches in evolutionary time. Science 285: 1265-1267.

Peterson, A.T., S.L. Egbert, V. Sánchez-Cordero \& K. Price. 2000. Geographic analysis of conservation priority: endemic birds and mammals in Veracruz, México. Biol. Conserv. 93: 85-94.

Peterson, A.T., D.R.B. Stockwell \& D.A. Kluza. 2002. Distributional prediction based on ecological niche modeling of primary occurrence data, p. 617-623. In M. Scott (ed.). Predicting species occurrences: issues of scale and accuracy. Island, Washington, D.C., EE.UU.

Peterson, A.T., J. Soberón, R.G. Pearson, R.P. Anderson, E. Martínez-Meyer, M. Nakamura \& M. Bastos Araújo. 2011. Ecological Niches and Geographic Distributions. Princeton University, Nueva Jersey, EE.UU.

Phillips, S.J., R.P. Anderson \& R.E. Schapire. 2006. A maximum entropy modelling of species geographic distributions. Ecol. Mod. 190: 231-259.

Pimm, S.L., G.J. Russell, J.L. Gittleman \& T.M. Brooks. 1995. The future of biodiversity. Science 269: 347-350

Pires, L., Y.L.R. Leite, G.A.B. da Fonseca \& M. Tavares da Fonseca. 2000. Biogeography of South American forest mammals: endemism and diversity in the Atlantic Forest. Biotropica 32: 872-881.

Porzecanski, A.L. \& J. Cracraft. 2005. Cladistic analysis of distributions and endemism (CADE): using raw distributions of birds to unravel the biogeography of the South American aridlands. J. Biogeogr. 32: 261-275.

Posadas, P. 1996. Distributional patterns of vascular plants in Tierra del Fuego: a study applying Parsimony Analysis of Endemicity (PAE). Biogeographica 72: 161-177.

Posadas, P. \& D.R. Miranda-Esquivel. 1999. El PAE (Parsimony Analysis of Endemicity) como una herramienta en la evaluación de la biodiversidad. Rev. Chil. Hist. Nat. 72: 539-546.

Prance, G.T. (ed.) 1982. Biological diversification in the tropics. Columbia University, Nueva York, EE.UU.

Prance, G.T. 1987. Biogeography of Neotropical plants, p. 46-65. In T.C. Whitmore \& G.T. Prance (eds.). Biogeography and quaternary history in tropical America. Oxford Monographs in Biogeography, Vol. 3. Clarendon, Oxford, Reino Unido.

Prum, R.O. 1988. Historical relationships among avian forest areas of endemism in the Neotropics. Proc. Int. Ornithol. Congr. 19: 2562-2572.

Ramírez-Morillo, I.R., G. Carnevali \& W. Cetzal-Ix. 2010. Hohenbergia mesoamericana (Bromeliaceae), first record of the genus for Mesoamerica. Rev. Mex. Biodiv. 81: 21-26.

Ramírez-Pulido, J. \& A. Castro-Campillo. 1990. Regionalización Mastofaunítica (mamíferos). Mapa IV.8.8.A. In Atlas Nacional de México, Vol. III. Instituto de Geografía-Universidad Nacional Autónoma de México, D.F., México.

Ramírez-Pulido, J., J. Arroyo-Cabrales \& A. Castro-Campillo. 2005. Estado actual y relación nomenclatural de los mamíferos terrestres de México. Acta Zool. Mex. 21: 21-82.

Ramírez-Pulido, J., A. Castro-Campillo, J. Arroyo-Cabrales \& F.A. Cervantes. 1996. Lista taxonómica de los mamíferos de México. Occas. Papers Mus. Texas Tech Univ. 158: 1-62.

Reeves, R.G. \& E. Bermingham. 2006. Colonization, population expansion, and lineage turnover: phylogeography of Mesoamerican characiform fish. Biol. J. Linn. Soc. 88: 235-255.

Reid, F.A. 1997. A field guide to mammals of Central America and Southeast Mexico. Oxford University, Nueva York, EE.UU.

Rican, O., R. Zardoya \& I. Doadrio. 2008. Phylogenetic relationships of Middle American cichlids (Cichlidae: Heroini) based on combined evidence from nuclear genes, mtDNA, and morphology. Mol. Phylogenet. Evol. 49: 941-957.

Richardson, J.E., R.T. Pennington, T.D. Pennington \& P.M. Hollingsworth. 2001. Rapid Diversification of a Species-Rich Genus of Neotropical Rain Forest Trees. Science 293: 2242-2245. 
Rodríguez, P., J. Soberón \& H.T. Arita. 2003. El componente beta de la diversidad de mamíferos de México. Acta Zool. Mex. 89: 241-259.

Rogers, D.S., C. Funk, J. Miller \& M. Engstrom. 2007. Molecular phylogenetic relationships among crestedtailed mice (Genus Habromys). J. Mamm. Evol. 14: $37-55$.

Rogers, R.D. 2003. Jurassic-Recent tectonic and stratigraphic history of the Chortis block of Honduras and Nicaragua (northern Central America). Tesis de Doctorado, Universidad de Texas, Austin, Texas, EE.UU.

Rojas-Soto, O.R., O. Alcántara-Ayala \& A.G. Navarro. 2003. Regionalization of the avifauna of the Baja California Peninsula, México: a parsimony analysis of endemicity and distributional modelling approach. J. Biogeogr. 30: 449-461.

Rosen, D.E. 1978. Vicariant patterns and historical explanation in biogeography. Syst. Zool. 27: 159-188.

Rosen, B.R. 1988. From fossils to Earth history: Applied Historical Biogeography, p. 437-481. In A.A. Myers \& P.S. Giller (eds.). Analytical biogeography. An integrated approach to the study of animal and plant distribution. Chapman and Hall, Londres, Reino Unido.

Rosen, B.R. 1992. Empiricism and the biogeographical black box: Concepts and methods in marine palaeobiogeography. Palaeogeogr. Palaeocl. 92: 171-205.

Rosen, B.R. \& A.B. Smith. 1988. Tectonics from fossils? Analysis of reef-coral and sea-urchin distributions from late Cretaceous to Recent, using a new method. Gondwana and Tethys, p. 275-306. In M.G. AudleyCharles \& A. Hallam (eds.). Special Publication of Geological Society, Londres, Reino Unido.

Rull, V. 1998, Biogeographical and evolutionary considerations of Mauritia (Arecaceae), based on palynological evidence. Rev. Paleobot. Palynol. 100: 109-122.

Ryan, R.M. 1963. The biotic provinces of Central America. Acta Zool. Mex. 6: 1-54.

Rylands, A.B., R.A. Mittermeier, J. Hines, C. Groves \& L. Cortés-Ortiz. 2005. Taxonomy and distributions of Mesoamerican primates, p. 29-79. In A. Estrada, P.A. Garber, M.S.M. Pavelka \& L. Luecke (eds.). New Perspectives in the Study of Mesoamerican Primates: Distribution, Ecology, Behavior and Conservation. Developments in Primatology. Springer, Nueva York, EE.UU.

Rzedowski, J. 1981. Vegetación de México. Limusa, D.F., México.

Rzedowski, J. 1990. Vegetación Potencial. Atlas Nacional de México, Sección Naturaleza. Hoja IV.8.2, Vol. II. Mapa escala: 1:4000 000. Instituto de GeografíaUniversidad Nacional Autónoma de México, D.F., México.
Rzedowski, J. 1991. El endemismo en la flora fanerogámica mexicana: una apreciación analítica preliminar. Acta Bot. Mex. 15: 47-64.

Rzedowski, J. 1993. Diversity and origins of the fanerogamic flora of Mexico, p. 129-144. In T.P. Ramamoorthy, R. Bye, A. Lot \& J. Fa (eds.). Biological diversity of Mexico: origins and distribution. Oxford University, Nueva York, EE.UU.

Samek, V. 1988. Fitorregionalización del Caribe. Rev. Jard. Bot. Nal. Cub. 9: 25-38.

Samudio, R. Jr. 2002. Mamíferos de Panamá, p. 415-451. In G. Ceballos \& J.A. Simonetti (eds.). Diversidad y conservación de los mamíferos neotropicales. Comisión Nacional para el Conocimiento y Uso de la Biodiversidad, Universidad Nacional Autónoma de México, D.F., México.

Sánchez-Cordero, V., P. Illoldi-Rangel, M. Linaje, S. Sarkar \& A.T. Peterson. 2005. Deforestation and extant distributions of Mexican endemic mammals. Biol. Conserv. 126: 465-473.

Sánchez-González, L.A., J.J. Morrone \& A.G. NavarroSigüenza. 2008. Distributional patterns of the Neotropical humid montane forest avifaunas. Biol. J. Linn. Soc. 94: 175-194.

Sánchez-Osés, C. \& R. Pérez-Hernández. 2005. Historia y tabla de equivalencias de las propuestas de subdivisiones biogeográficas de la región Neotropical, p. 145-169. In J. Llorente-Bousquets \& J.J. Morrone (eds.). Regionalización biogeográfica en Iberoamérica y tópicos afines: Primeras Jornadas Biogeográficas de la Red Iberoaméricana de Biogeografía y Entomología Sistemática (RIBES XII.I-CYTED). Facultad de Ciencias - Universidad Nacional Autónoma de México, D.F., México.

Santos, C.M.D. 2005. Parsimony analysis of endemicity: Time for an epitaph? J. Biogeogr. 32: 1284-1286.

Santos, C.M.D. \& D.S. Amorim. 2007. Why biogeographical hypotheses need a well supported phylogenetic framework: A conceptual evaluation. Pap. Avul. Zool. 47: 63-73.

Saslis-Lagoudakis, C., M.W. Chase, D.N. Robinson, S.J. Russell \& B.B. Klitgaard. 2008. Phylogenetics of Neotropical Platymiscium (Leguminosae: Dalbergieae): systematics, divergence times, and biogeography inferred from nuclear ribosomal and plastid DNA sequence data. Am. J. Bot. 95: 1270-1286.

Savage, J.M. 1966. The origins and history of the Central America herpetofauna. Copeia 4: 719-766.

Savage, J.M. 1974. The isthmian link and the evolution of Neotropical mammals. Contrib. Sci. Los Angeles Country Mus. Nat. Hist. 260: 1-51.

Savage, J.M. 1982. The enigma of the Central American herpetofauna: dispersal or vicariance? Ann. Mo. Bot. Gard. 69: 464-547. 
Savage, J.M. 2002. The amphibians and reptiles of Costa Rica: a herpetofauna between two continents, between two seas. The University of Chicago, Chicago, EE.UU.

Scachetti-Pereira, R. 2003. Desktop GARP User's Manual version 1.1.6. University of Kansas Biodiversity Research Center. http://beta.lifemapper.org/ desktopgarp/

Schmidt, C.A., M.D. Engstrom \& H.H. Genoways. 1989. Heteromys gaumeri. Mamm. Sp. 345: 1-4.

Schuster, J.C. 1992. Biotic areas and the distribution of passalid beetles (Coleoptera) in northern Central America: Post-Pleistocene Montane Refuges, p. 285292. In S.P. Darwin \& A.L. Welden (eds.). Biogeography of Mesoamerica: proceedings of a symposium, Mérida, Yucatán, México, October 26-30, 1984. Tulane studies in zoology and botany. Supplementary publication 1 .

Schuster, J.C., E.B. Cano \& P. Reyes-Castillo. 2003. Proculus, gigant Latin-American passalids revision, phylogeny and biogeography. Acta Zool. Mex. 90: 281-306.

Scott, J.M., E.A. Norse, H.T. Arita, A. Dobson, J.A. Esyes, M. Foste, B. Gilbert, D. Jensen, R.L. Knight, D. Mattson \& M.E. Soulé. 1999. The issue of scale in selecting and designing biological reserves, p. 19-37. In M.E. Soulé \& J. Terborgh (eds.). Continental Conservation, scientific foundations of regional reserve networks. Washington, D.C., EE.UU.

Selander, R.B. \& P. Vaurie. 1962. A Gazetteer to Accompany the "Insecta" Volumes of the "Biologia CentraliAmericana”. Am. Mus. Nov. 2099: 1-70.

Silva-Lópes, G., J. Motta-Gill \& A.I. Sánchez Hernández. 1996. Taxonomic notes on Ateles geoffroyi. Neotrop. Primates 4: 41-44.

Simpson, B.G. \& J. Haffer. 1978. Speciation patterns in the Amazonian forest biota. Annu. Rev. Ecol. Syst. 9: 497-518

Soberón, J. \& A.T. Peterson. 2004. Biodiversity informatics: managing and applying primary biodiversity data. Philos. T. Roy. Soc. B 359: 689-698.

Soberón, J. \& A.T. Peterson. 2005. Interpretation of models of fundamental ecological niches and species' distributional areas. Biodivers. Inform. 2: 1-10.

Standley, P.C. 1930. Flora of Yucatán. Publ. Field Mus. Nat. Hist. Bot. Ser. 3: 157-492.

Stockwell, D.R.B. 1999. Genetic Algorithms II, p. 123-144 In A.H. Fielding (ed.). Machine Learning Methods for Ecological Applications. Kluwer Academic, Boston, EE.UU.

Stockwell, D.R.B. \& I.R. Noble. 1992. Induction of sets of rules from animal distribution data: a robust and informative methos of data analysis. Math. Comput. Simulat. 32: 249-254.
Stockwell, D. \& D. Peters. 1999. The GARP modelling system: problems and solutions to automated spatial prediction. Int. J. Geogr. Inf. Sci. 13: 143-158.

Stockwell, D.R.B. \& A.T. Peterson. 2002a. Controlling bias during predictive modeling with museum data, p. 537-546. In J.M. Scott, P.J. Heglund, M. Morrison, M. Raphael, J. Haufler, B. Wall (eds.). Predicting Species Occurrences: Issues of Scale and Accuracy. Island, Covello, California, EE.UU.

Stockwell, D.R.B. \& A.T. Peterson. 2002b. Effects of sample size on accuracy of species distribution models. Ecol. Mod. 148: 1-13.

Tejedor, A. 2005. A new species of funnel-eared bat (Natalidae: Natalus) from Mexico. J. Mamm. 86: 1109-1120.

Toledo, V.M. 1982. Pleistocene changes of vegetation in Tropical Mexico, p. 93-111. In G.T. Prance (ed.). Biological Diversification in the Tropics. Columbia University, Nueva York, EE.UU.

Toledo, V.M., J. Rzedowski, J. Villa-Lobos, L.D. Gómez, J.C. Godoy \& O. Herrera-Macbryde. 1997. Regional overview: Middle America, p. 97-124. In S.D. Davis, V.H. Heywood, O. Herrera-Macbryde, J. Villa-Lobos \& A.C. Hamilton (eds.). Centres of Plant Diversity: A Guide and Strategy for their Conservation. Vol. 3. The Americas. Oxford, Reino Unido, World Wide Fund for Nature, IUCN-The World Conservation Union.

Trejo-Torres, J.C. \& J.D. Ackerman. 2001. Biogeography of the Antilles based on a parsimony analysis of orchid distributions. J. Biogeogr. 28: 775-794.

Trénel, P., M.H.G. Gustafssona, W.J. Bakerb, C.B. Asmussen-Langec, J. Dransfieldb \& F. Borchsenius. 2007. Mid-Tertiary dispersal, not Gondwanan vicariance explains distribution patterns in the wax palm subfamily (Ceroxyloideae: Arecaceae). Mol. Phylogenet. Evol. 45: 272-288.

Urquiza-Haas, T., W. Tobón \& P. Koleff. 2011. Sitios prioritarios para la conservación de mamíferos terrestres: evaluación de los criterios de selección de indicadores, p. 131-149. In P. Koleff \& T. Urquiza-Haas (coords.). Planeación para la conservación de la biodiversidad terrestre en México: retos en un país megadiverso. CONABIO-CONANP, D.F., México.

Vane-Wright, R.I., C.J. Humphries \& P.H. Williams. 1991. What to protect? - Systematics and the agony of choice. Biol. Conserv. 55: 235-254.

Vázquez-Miranda, H., A.G. Navarro-Sigüenza \& J.J. Morrone. 2007. Biogeographical patterns of the avifaunas of the Caribbean Basin Islands: a parsimony perspective. Cladistics 22: 1-21.

Villa-R., B. \& F.A. Cervantes. 2003. Los mamíferos de México. Iberoamérica, Instituto de Biología - Universidad Nacional Autónoma de México, D.F., México. 
Wagner, P.L. 1964. Natural vegetation of Middle America, p. 216-264. In R. Wauchope (ed.). Handbook of Middle American Indians. University Texas, Austin, Texas, EE.UU.

Wahlberg, N. \& A.V.L. Freitas. 2007. Colonization of and radiation in South America by butterflies in the subtribe Phyciodina (Lepidoptera: Nymphalidae). Mol. Phylogenet. Evol. 44: 1257-1272.

Wake, D.B., T.J. Papenfuss \& J.F. Lynch. 1992. Distribution of salamanders along elevational transects in Mexico and Guatemala, p. 303-319. In S.P. Darwin \& A.L. Welden (eds.). Biogeography of Mesoamerica: proceedings of a symposium, Mérida, Yucatán, México, October 26-30, 1984. Tulane studies in zoology and botany. Supplementary publication 1 .

Wang, I.J., A.J. Crawford \& E. Bermingham. 2008. Phylogeography of the Pygmy Rain Frog (Pristimantis ridens) across the lowland wet forests of isthmian Central America. Mol. Phylogenet. Evol. 47: 992-1004.

Watson, D.M. \& A.T. Peterson. 1999. Determinants of diversity in a naturally fragmented landscape: humid montane forest avifaunas of Mesoamerica. Ecography 22: 582-589.

Weigt, L.A., A.J. Crawford, A.S. Rand \& M.J. Ryan. 2005. Biogeography of the túngara frog, Physalaemus pustulosus: a molecular perspective. Mol. Ecol. 14: 3857-3876.

Weir, J.T., E. Berminghamb \& D. Schlutera. 2009. The Great American Biotic Interchange in birds. P. Natl. Acad. Sci. USA 106: 21737-21742.

Wendt, T. 1989. Las selvas de Uxpanapa, Veracruz-Oaxaca, México: evidencia de refugios florísticos cenozóicos. An. Inst. Biol. UNAM Ser. Bot. 58: 29-54.

Wendt, T. 1993. Composition, floristic affinities, and origins of the canopy tree flora of the Mexican Atlantic slope rain forests, p. 595-680. In T.P. Ramamoorthy, R. Bye, A. Lot \& J. Fa (eds.). Biological Diversity of Mexico: Origins and Distribution. Oxford University, Nueva York, EE.UU.
Wiley, E.O., K.M. McNyset, A.T. Peterson, C.R. Robins \& A.M. Stewart. 2003. Niche modeling and geographic range predictions in the marine environment using a machinelearning algorithm. Oceanography 16: $120-127$

Wilson, D.E. \& D.M. Reeder. 1993. Mammal Species of the World: a taxonomic and geographic reference. Smithsonian Institution, Washington, EE.UU - Londres, Reino Unido.

Wilson, D.E. \& D.M. Reeder. 2005. Mammal Species of the World: a taxonomic and geographic reference. Vols. I y II. The Johns Hopkins University, Baltimore, EE.UU.

Wilson, D.E., R.M. Timm \& F.A. Chinchilla. 2002. Mamíferos de Costa Rica, p. 227-253. In G. Ceballos \& J.A. Simonetti (eds.). Diversidad y Conservación de los Mamíferos Neotropicales. Comisión Nacional para el Conocimiento y Uso de la Biodiversidad y Universidad Nacional Autónoma de México, D.F., México.

Wilson, L.D. \& J.D. Johnson. 2010. Distributional patterns of the herpetofauna of Mesoamerica, a biodiversity hotspot, p. 31-98. In L.D. Wilson, J.H. Townsend \& J.D. Johnson (eds.). Conservation of Mesoamerican amphibians and reptiles. Eagle Mountains, Utah, EE.UU.

Wüster, W., J.E. Ferguson, J.A. Quijada-Mascareñas, C.E. Pook, M. Da Graça Salomão \& R.S. Thorpe 2005. Tracing an invasion: landbridges, refugia, and the phylogeography of the Neotropical rattlesnake (Serpentes: Viperidae: Crotalus durissus). Mol. Ecol. 14: 1095-1108.

Zamudio, K.R. \& H.W. Greene. 1997. Phylogeography of the bushmaster (Lachesis muta: Viperidae): implications for Neotropical biogeography, systematics, and conservation. Biol. J. Linn. Soc. 62: 421-442.

Zeh, J.A., D.W. Zeh \& M.M. Bonilla. 2003. Phylogeography of the harlequin beetle-riding pseudoscorpion and the rise of the Isthmus of Panama. Mol. Ecol. 12: $2759-2769$. 


\section{APÉNDICE 1}

Mamíferos reconocidos en el BTP de Mesoamérica, conforme a la propuesta de Wilson \& Reeder (2005)

\section{APPENDIX 1}

Mammals recorded in Mesoamerica TEF, as proposed by Wilson \& Reeder (2005)

En esta lista se incluye la distribución de cada especie, con base en Hall (1981), Reid (1997), Ceballos et al. (2005) y Wilson \& Reeder (2005), así como de los MNE generados en el presente proyecto. El número de localidades únicas para generar los MNE se encuentra después de la especie y entre paréntesis. Las especies endémicas a Mesoamérica se indican con asterisco (*) y las especies de las que no se obtuvo suficientes datos para los MNE se señalan con $(\dagger)$.

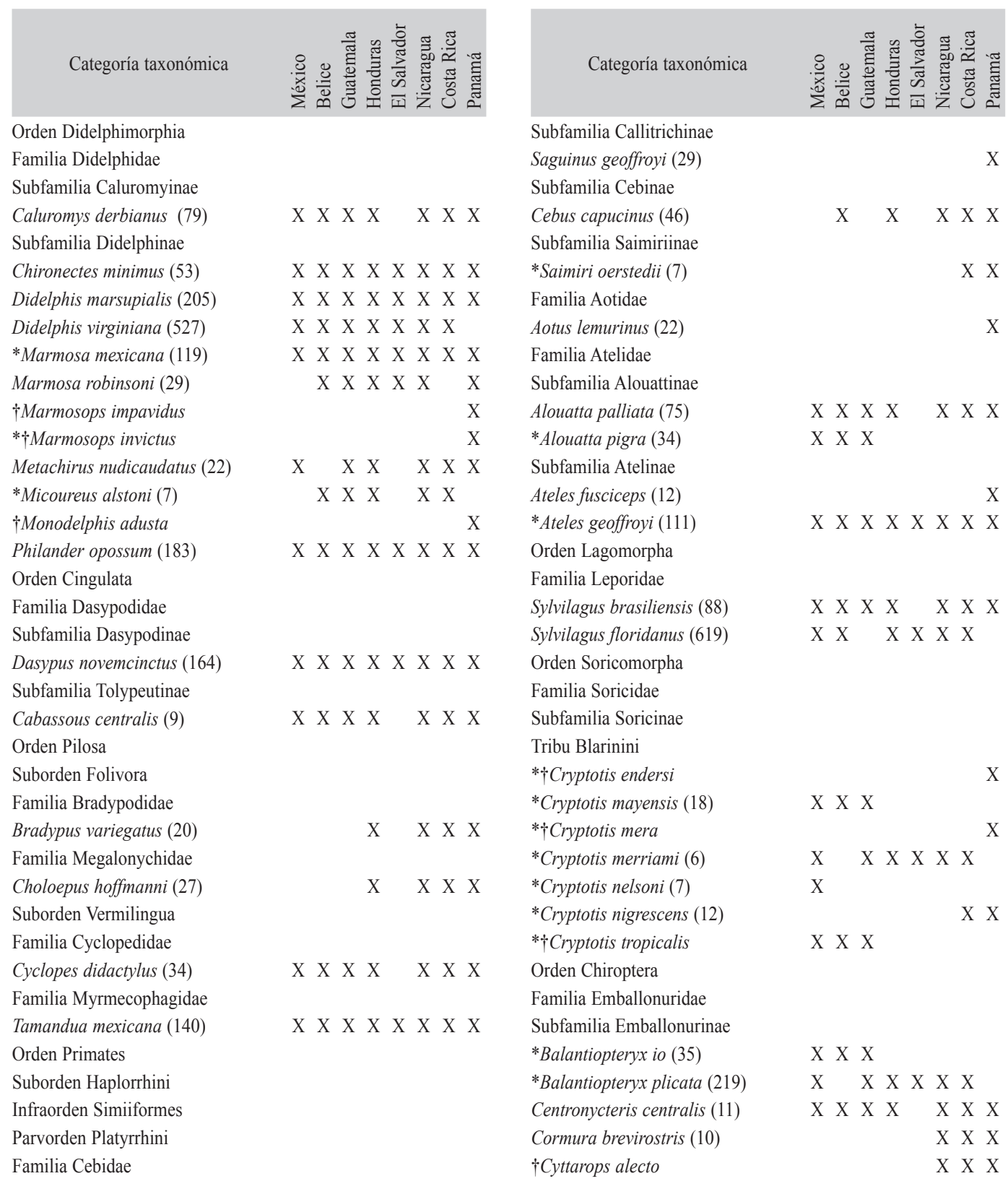




$\quad$ Categoría taxonómica
Diclidurus albus (15)
Peropteryx kappleri (14)
Peropteryx macrotis (44)
Rhynchonycteris naso (52)
Saccopteryx bilineata (152)
Saccopteryx leptura (10)
Familia Phyllostomidae
Subfamilia Desmodontinae
Desmodus rotundus (658)
Diaemus youngi $(9)$
Diphylla ecaudata (77)
Subfamilia Glossophaginae
Tribu Glossophagini
Anoura cultrata (11)
Choeroniscus godmani (30)
Glossophaga commissarisi (161)
Glossophaga soricina (542)
*Hylonycteris underwoodi (59)
Lichonycteris obscura (16)
Tribu Lonchophyllini
†Lionycteris spurrelli
†Lonchophylla mordax
Lonchophylla robusta (12)
†Lonchophylla thomasi
Subfin

Subfamilia Phyllostominae Gray, 1852

Chrotopterus auritus (27)

$\dagger$ Glyphonycteris daviesi

Glyphonycteris sylvestris (12)

Lampronycteris brachyotis (14)

Lonchorhina aurita (29)

Lophostoma brasiliense (27)

*Lophostoma evotis (11)

Lophostoma silvicolum (13)

Macrophyllum macrophyllum (15)

Micronycteris hirsuta (16)

Micronycteris microtis (153)

Micronycteris minuta (5)

Micronycteris schmidtorum (10)

Mimon cozumelae (52)

Mimon crenulatum (9)

Phylloderma stenops (8)

Phyllostomus discolor (71)

Phyllostomus hastatus (32)

$\dagger$ Tonatia saurophila

Trachops cirrhosus (75)

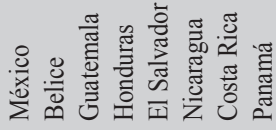

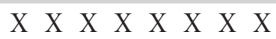

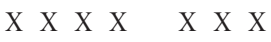

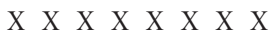

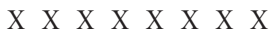

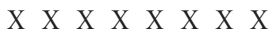

X X X X X X X X

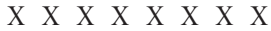

$X \quad X \quad X \quad X \quad X \quad X \quad X$

$X \quad X \quad X \quad X \quad X \quad X$

$\mathrm{X} \mathrm{X}$

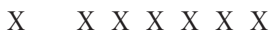

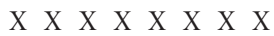

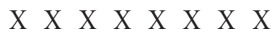

$X X X X \quad X X X$

X X X X X X

$$
\begin{array}{rrr} 
& X \\
& X & X \\
X & X & X \\
& X
\end{array}
$$

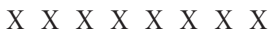
$X \quad X \quad X \quad X$

$\mathrm{X} \quad \mathrm{X}$ X $\quad \mathrm{X}$ X $\mathrm{X}$

$\begin{array}{lllllllllllll}X & X & X & X & X\end{array}$

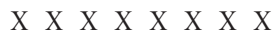

X X X X X X X

X X X X

$\begin{array}{llll}X & X & X\end{array}$

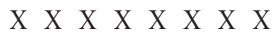

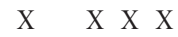

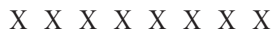

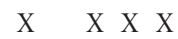

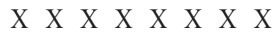

$\begin{array}{lllll}X & X & X & X\end{array}$

$\begin{array}{llll}X & X & X & X\end{array}$

$X X X X \quad X X X$

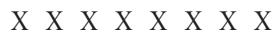

$X X X \quad X X$

$\begin{array}{lllllllllllll}X & X & X & X & X\end{array}$

X X X X X X X X

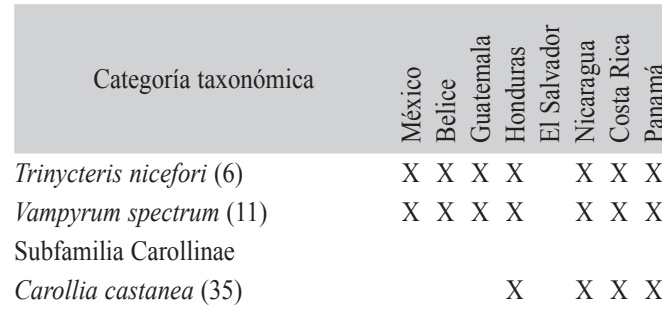

Carollia perspicillata (224)

*Carollia sowelli (242)

*Carollia subrufa (98)

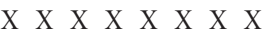

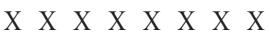

$\mathrm{X} \quad \mathrm{X} \quad \mathrm{X} \quad \mathrm{X} \quad \mathrm{X} \quad \mathrm{X} \quad \mathrm{X}$

Subfamilia Stenodermatinae

Tribu Sturnirini

Sturnira lilium (557)

Sturnira ludovici (374)

Sturnira luisi (6)

* $\uparrow$ Sturnira mordax

Tribu Stenodermatini

$\uparrow$ Ametrida centurio

*†Artibeus inopinatus

Artibeus jamaicensis (769)

Artibeus lituratus (605)

Artibeus phaeotis (337)

Artibeus watsoni (64)

Centurio senex (152)

$\uparrow$ Chiroderma trinitatum

Chiroderma villosum (87)

*Ectophylla alba (7)

Mesophylla macconnelli (5)

$\uparrow$ Platyrrhinus dorsalis

Platyrrhinus helleri (97)

Platyrrhinus vittatus (12)

Uroderma bilobatum (107)

Vampyressa nymphaea (10)

Vampyressa thyone (45)

Vampyrodes caraccioli (24)

Familia Mormoopidae

Mormoops megalophylla (202)

Pteronotus davyi (204)

Pteronotus gymnonotus (14)

Pteronotus parnellii (378)

Pteronotus personatus (89)

Familia Noctilionidae

Noctilio albiventris (21)

Noctilio leporinus (69)

Familia Furipteridae

$\uparrow$ Furipterus horrens

Familia Thyropteridae

$\dagger$ Thyroptera discifera

Thyroptera tricolor (12)

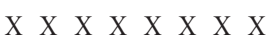

$X \quad X \quad X \quad X \quad X \quad X$

$\mathrm{X} X$

$\mathrm{X} X$

X

$\begin{array}{llll}X & X & X\end{array}$

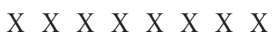

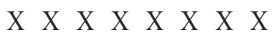

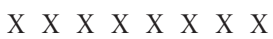

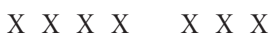

X X X X X X X X

$X$

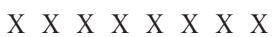
$\mathrm{X}$ X X X $\mathrm{X} X \mathrm{X}$

$\mathrm{X}$

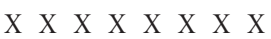
$X \mathrm{X}$

X X X X X X X X $X X X$

$\begin{array}{llllll}X & X & X & X & X\end{array}$ X X X X X X X

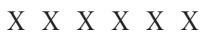

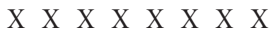

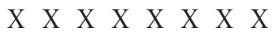

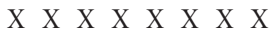
X X X X X X X X

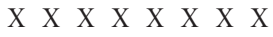
X X X X X X X X

X X X

$\mathrm{X} X \mathrm{X}$

X X X X X X X 
APÉNDICE 1 (Continuación) / APPENDIX 1 (Continued)

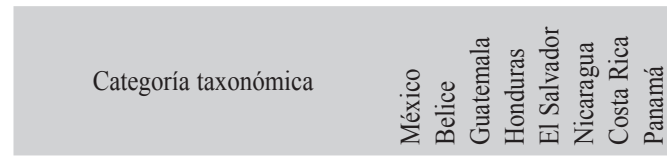

Familia Natalidae

Natalus stramineus (71)

Familia Molossidae

Subfamilia Molossinae

Cynomops mexicanus (8)

$\uparrow$ Cynomops planirostris

Eumops auripendulus (19)

Eumops bonariensis (13)

$\dagger$ Eumops hansae

Eumops underwoodi (13)

Molossus currentium (9)

Molossus pretiosus (6)

Molossus rufus (214)

Molossus sinaloae (56)

Nyctinomops laticaudatus (46)

Promops centralis (20)

Familia Vespertilionidae

Subfamilia Vespertilioninae

Tribu Eptesicini

Eptesicus brasiliensis (20)

Eptesicus furinalis (85)

Tribu Lasiurini

* $\uparrow$ Lasiurus castaneus

Lasiurus ega (49)

$\uparrow$ Lasiurus egregius

Tribu Nycticeiini

*Rhogeessa aeneus (7)

Rhogeessa io (8)

*Rhogeessa tumida (97)

Tribu Pipistrellini

Pipistrellus subflavus (24)

Subfamilia Antrozoinae

*Bauerus dubiaquercus (12)

Subfamilia Myotinae

Myotis albescens (11)

*Myotis elegans (26)

*Myotis fortidens (75)

Myotis keaysi (106)

Myotis nigricans (100)

Myotis oxyotus (6)

Myotis riparius (13)

Orden Carnivora

Suborden Feliformia

Familia Felidae

Subfamilia Felinae

Leopardus pardalis (105)

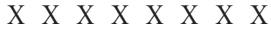

X X X X X X

$\mathrm{X}$

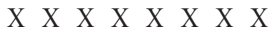

X X X X X X X

X $\quad X \quad X \quad X \quad X \quad X$

$X \quad X \quad X \quad X$

$X \quad X \quad X X X$

$\begin{array}{lllll}X & X & X & X\end{array}$

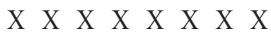

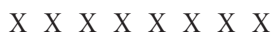

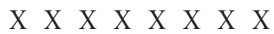

$X \quad X X \quad X \quad X$

$\begin{array}{llllll}X & X & X & X & X & X\end{array}$

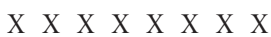

$X X$

X X X X X X X X

$\mathrm{X}$

X

$\mathrm{X} X$

X X X X X X X

X X X X

X X X X X X

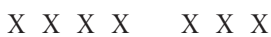

X X X X X X X

$\mathrm{X} X$

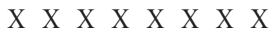

$X \quad X \quad X \quad X \quad X \quad X$

$\mathrm{X} X$

$\mathrm{X} \quad \mathrm{X} X$

X X X X X X X X

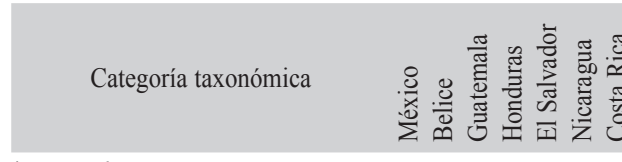

$†$ Leopardus tigrinus

Leopardus wiedii (67)

Puma concolor (88)

Puma yagouaroundi (93)

$X$

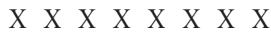

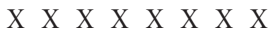

X X X X X X X X

Subfamilia Pantherinae

Panthera onca (88)

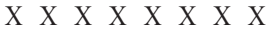

Suborden Caniformia

Familia Canidae

Canis latrans (294)

$\dagger$ Speothos venaticus

Urocyon cinereoargenteus (426)

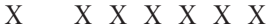

$\mathrm{X}$

Familia Mustelidae

Subfamilia Lutrinae

Lontra longicaudis (193)

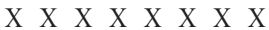

Subfamilia Mustelinae

Eira barbara (62)

Galictis vittata (23)

Mustela frenata (199)

Familia Mephitidae

Conepatus leuconotus (245)

Conepatus semistriatus (28)

Familia Procyonidae

$\uparrow$ Bassaricyon gabbii

* Bassariscus sumichrasti (50)

$\begin{array}{llll}X & X\end{array}$

Nasua narica (302)

Potos flavus (193)

Procyon cancrivorus (7)

Procyon lotor (289)

Orden Perissodactyla

Familia Tapiridae

Tapirus bairdii (46)

Orden Artiodactyla

Familia Tayassuidae

Pecari tajacu (187)

Tayassu pecari (32)

Familia Cervidae

Subfamilia Capreolinae

* Mazama pandora (19)

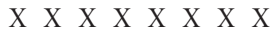

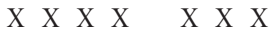

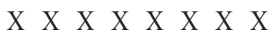

X X X X X

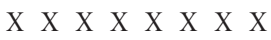

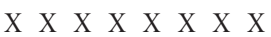

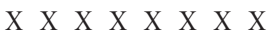

$X \quad X$

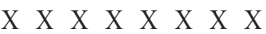

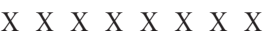

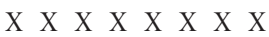

$X X X \quad X \quad X$

Mazama temama (80)

$\mathrm{X}$

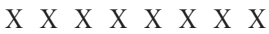

Odocoileus virginianus (406)

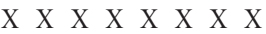

Orden Rodentia

Suborden Sciuromorpha

Familia Sciuridae

Subfamilia Sciurinae

Tribu Sciurini

Microsciurus alfari (27) 
APÉNDICE 1 (Continuación) / APPENDIX 1 (Continued)

\begin{tabular}{|c|c|c|c|c|c|c|c|c|c|}
\hline Categoría taxonómica & 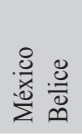 & 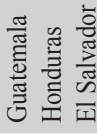 & 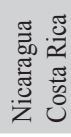 & 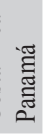 & Categoría taxonómica & 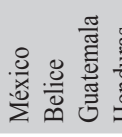 & 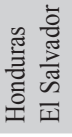 & 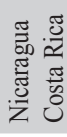 & 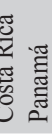 \\
\hline$\dagger$ Microsciurus mimulus & & & & $\mathrm{X}$ & Tribu Oryzomyini & & & & \\
\hline *Sciurus aureogaster (436) & $\mathrm{X}$ & $\mathrm{X}$ & & & Melanomys caliginosus (59) & & $\mathrm{X}$ & $X X$ & $X \quad X$ \\
\hline *Sciurus deppei (244) & $\mathrm{X} X$ & $\mathrm{X} X \mathrm{X}$ & $\mathrm{X} X$ & & $* \uparrow$ Neacomys pictus & & & & $\mathrm{X}$ \\
\hline Sciurus granatensis (68) & & & $\mathrm{X}$ & $X$ & $\dagger$ Oecomys bicolor & & & & $\mathrm{X}$ \\
\hline *Sciurus richmondi (10) & & & $\mathrm{X}$ & & $\dagger$ Oecomys trinitatis & & & $\mathrm{X}$ & $X \quad X$ \\
\hline *Sciurus variegatoides (101) & $\mathrm{X}$ & X X X & $X X$ & $\mathrm{X}$ & Oligoryzomys fulvescens (249) & X $\quad X \quad X \quad Y$ & X X & $X X$ & $X \quad X$ \\
\hline *Sciurus yucatanensis (51) & X X & $X$ & & & Oryzomys alfaroi (157) & X X X I & X X & $X X$ & $X \quad X$ \\
\hline *†Syntheosciurus brochus & & & $\mathrm{X}$ & $\mathrm{X}$ & Oryzomys bolivaris (11) & & $X$ & $X X$ & $X \quad X$ \\
\hline Familia Heteromyidae & & & & & Oryzomys couesi (652) & $\mathrm{X} \quad \mathrm{X} \quad \mathrm{X}$ & $\mathrm{X} X$ & $\mathrm{X} X$ & $X \quad X$ \\
\hline Subfamilia Heteromyinae & & & & & *Oryzomys devius (34) & & & $\mathrm{X}$ & $X X$ \\
\hline Heteromys australis (7) & & & & $\mathrm{X}$ & *Oryzomys rostratus (19) & $\mathrm{X} \quad \mathrm{X} \quad \mathrm{X}$ & $\mathrm{X} X$ & $\mathrm{X}$ & \\
\hline Heteromys desmarestianus (200) & X X & X X X & $X X$ & $\mathrm{X}$ & Oryzomys talamancae (35) & & & & $X \quad X$ \\
\hline *Heteromys gaumeri $(77)$ & $\mathrm{X} X$ & $\mathrm{X}$ & & & Tribu Thomasomyini & & & & \\
\hline *Liomys adspersus (19) & & & & $\mathrm{X}$ & $*_{\dagger}+$ Rhipidomys latimanus & & & & $\mathrm{X}$ \\
\hline Familia Geomyidae & & & & & Subfamilia Tylomyinae & & & & \\
\hline *Orthogeomys cavator $(10)$ & & & $\mathrm{X}$ & $\mathrm{X}$ & Tribu Nyctomyini & & & & \\
\hline *Orthogeomys cherriei (18) & & & $\mathrm{X}$ & & *Nyctomys sumichrasti (92) & $\mathrm{X} \quad \mathrm{X} \quad \mathrm{X}$ & $\mathrm{X} X$ & $X X$ & $X \quad X$ \\
\hline${ }^{*} \dagger$ Orthogeomys dariensis & & & & $\mathrm{X}$ & *Otonyctomys hatti (10) & X X X & & & \\
\hline *Orthogeomys grandis $(73)$ & $\mathrm{X}$ & X X X & & & Tribu Tylomyini & & & & \\
\hline *Orthogeomys hispidus (131) & $\mathrm{X} X$ & $\mathrm{X} X$ & & & *Ototylomys phyllotis (163) & $\mathrm{X} X \mathrm{X}$ & $\mathrm{X} X$ & $X X$ & $X$ \\
\hline *†Orthogeomys lanius & $\mathrm{X}$ & & & & *Tylomys nudicaudus (53) & $\mathrm{X} X \mathrm{X}$ & $\mathrm{X} X$ & $\mathrm{X}$ & \\
\hline *†Orthogeomys matagalpae & & $\mathrm{X}$ & $\mathrm{X}$ & & *Tylomys watsoni $(20)$ & & & $\mathrm{X}$ & $X \quad X$ \\
\hline${ }^{*} \dagger$ Orthogeomys underwoodi & & & $\mathrm{X}$ & & Suborden Hystricomorpha & & & & \\
\hline Superfamilia Muroidea & & & & & Infraorden Hystricognathi & & & & \\
\hline Familia Cricetidae & & & & & Familia Erenthizontidae & & & & \\
\hline Subfamilia Neotominae & & & & & Subfamilia Erethizontinae & & & & \\
\hline Tribu Neotomini & & & & & *Coendou rothschildi (12) & & & & \\
\hline Neotoma mexicana (412) & $\mathrm{X}$ & $\mathrm{X} X \mathrm{X}$ & & & *Sphiggurus mexicanus (83) & $\mathrm{X} \quad \mathrm{X} \quad \mathrm{X}$ & $\mathrm{X} X$ & $X X$ & $X \quad X$ \\
\hline Tribu Reithrodontomyini & & & & & Familia Caviidae & & & & \\
\hline$*_{\dagger} \dagger$ Isthmomys flavidus & & & & $X$ & Subfamilia Hydrochoerinae & & & & \\
\hline Isthmomys pirrensis (9) & & & & $\mathrm{X}$ & $\dagger$ Hydrochoerus isthmius & & & & $\mathrm{X}$ \\
\hline *Peromyscus gymnotis (14) & $\mathrm{X}$ & X X X & $\mathrm{X}$ & & Familia Dasyproctidae & & & & \\
\hline Peromyscus leucopus (516) & $\mathrm{X}$ & & & & *Dasyprocta mexicana (24) & $\mathrm{X}$ & & & \\
\hline *Peromyscus mexicanus (534) & $\mathrm{X} X$ & $\mathrm{X} X \mathrm{X}$ & $X X$ & $\mathrm{X}$ & Dasyprocta punctata (115) & $\mathrm{X} X \mathrm{X}$ & $\mathrm{X} X$ & $X X$ & $X X$ \\
\hline *Peromyscus stirtoni (7) & & X X X & $\mathrm{X}$ & & Familia Cuniculidae & & & & \\
\hline *Peromyscus yucatanicus (63) & $X$ & & & & Cuniculus paca (95) & $\mathrm{X} X \mathrm{X}$ & X X & $X X$ & $X \quad X$ \\
\hline${ }^{*} \dagger$ Reithrodontomys brevirostris & & & $X X$ & & Familia Echimyidae & & & & \\
\hline *Reithrodontomys gracilis (55) & $\mathrm{X}$ & & & & Subfamilia Echimyinae & & & & \\
\hline${ }^{*} \dagger$ Reithrodontomys paradoxus & & & $X X$ & & Diplomys labilis (7) & & & & $\mathrm{X}$ \\
\hline Subfamilia Sigmodontinae & & & & & Subfamilia Eumysopinae & & & & \\
\hline Tribu Ichthyomyini & & & & & Hoplomys gymnurus (20) & & $\mathrm{X}$ & X X & $X \quad X$ \\
\hline$\dagger$ Ichthyomys tweedii & & & & $\mathrm{X}$ & Proechimys semispinosus (61) & & $\mathrm{X}$ & $X X$ & $X \quad X$ \\
\hline
\end{tabular}


